\title{
Caspase-11 regulates lung inflammation in response to house dust mites
}

Arwa Abu khweek

Birzeit University https://orcid.org/0000-0001-8977-7673

Marisa R. Joldrichsen

Ohio State University

\section{Eunsoo Kim}

Ohio State University

\section{Zayed Attia}

Ohio State University

Kathrin Krause

Ohio State University

Kylene Daily

Ohio State University

Shady Estfanous

Ohio State University

Kaitlin Hamilton

Ohio State University

Asmaa Badr

Ohio State University

Midhun N. K. Anne

Ohio State University

Mostafa Eltobgy

Ohio State University

Cierra Carafice

Ohio State University

Xiaoli Zhang

Ohio State University

Mikhail A. Gavrilin

Ohio State University

Prosper N. Boyaka

Ohio State University

Amal 0. Amer ( $\square$ Amal.Amer@osumc.edu )

Ohio State University 
Research

Keywords:

Posted Date: July 24th, 2020

DOI: https://doi.org/10.21203/rs.3.rs-46816/v1

License: (c) (i) This work is licensed under a Creative Commons Attribution 4.0 International License. Read Full License 


\section{Abstract}

Asthma is an inflammatory lung disorder characterized by mucus hypersecretion, cellular infiltration, and bronchial hyper-responsiveness. House dust mites (HDM) are the most prevalent cause of allergic sensitization. Canonical and noncanonical inflammasomes are multiprotein complexes that assemble in response to pathogen or danger-associated molecular patterns (PAMPs or DAMPs). Murine caspase-11 engages the noncanonical inflammasome. We addressed the role of caspase-11 in mediating host

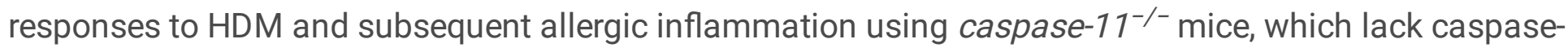
11 while express caspase-1. We found that HDM induce caspase-11 expression in vitro. The presence of

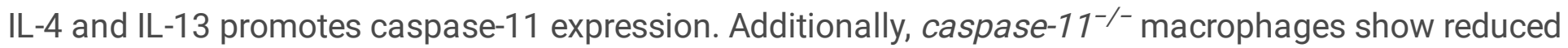
release of (KC, IL-6 and IL-12) cytokines, and express lower levels of costimulatory molecules (e.g., CD40,

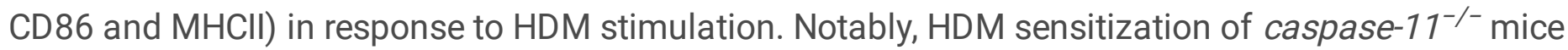
resulted in similar levels of IgE responses and hypothermia in response to nasal HDM challenge compared to WT. However, analysis of cell numbers and cytokines in bronchiolar alveolar fluid (BALF), as well as histological lung tissue showed altered inflammatory responses and reduced neutrophilia in the

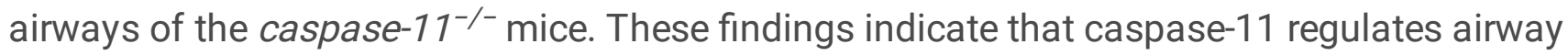
inflammation in response to HDM exposure.

\section{Introduction}

Asthma is a long-term recurring inflammatory lung disorder characterized by mucus hypersecretion, cellular infiltration, chronic airway inflammation and bronchial hyper-responsiveness (Platts-Mills and Chapman 1987, Arlian and Platts-Mills 2001, Thomas 2012). Different forms of asthma can coexist in some patients including atopic (allergic, Th2-dependent), and non-atopic (non-allergic, Th2-independent) forms. These forms are initiated and regulated by multiple genetic and environmental factors, such as HDM allergens.

House dust mites, such as Dermatophagoides pteronyssinus, are an unsurpassed cause of atopic sensitization and the major cause of allergic asthma worldwide (Calderon, Linneberg et al. 2015, Sanchez-Borges, Fernandez-Caldas et al. 2017). A battery of D. pteronyssinus allergens, proteases, bacterial lipopolysaccharide (LPS), and chitin from the mite exoskeleton are present in fecal pellets and decaying mite materials and have potent sensitizing capacities (Thomas, Hales et al. 2010, Bordas-Le Floch, Le Mignon et al. 2017). Proteases-dependent effect of mite allergens is associated with breaching the epithelial layer, breaking tight junctions and stimulating protease-activated receptors. These events lead to increased epithelium permeability and production of chemokines and cytokines, which recruits antigen presenting cells (APCs) into the epithelial layers, thus promoting airway inflammation and remodelling (Asokananthan, Graham et al. 2002, Kato, Takai et al. 2009, Jacquet 2011, Jacquet 2011, Kubo 2017). Even though $C D 4^{+}$Th2 cells orchestrate the HDM allergic response via production of IgE against mite allergens, promoting inflammation and lung remodelling ( $\mathrm{Na}$, Cho et al. 2016), it is now recognized that the innate immune system plays a fundamental role in initiating and shaping the allergic 
response by programming and maintaining Th2-biased adaptive immunity in response to HDM allergens and their contaminants (Hammad, Chieppa et al. 2009, Willart and Lambrecht 2009).

Innate immune system activation is mediated through pattern recognition receptors (PRRs), which sense PAMPs and DAMPs (Janeway and Medzhitov 2002, Kawai and Akira 2010). The PRR families include intracellular NOD-like receptors (NLRs) and extracellular Toll-like receptors (TLRs) (Kawai and Akira 2010). Sensing PAMPs or DAMPs by the NLR protein family, such as NLRP3 or NLRC4, mediates the assembly of inflammasomes. Downstream of inflammasome signaling, IL-1 $\beta$ and IL-18 are cleaved by active caspase-1 and delineates the canonical inflammasome pathway (Lamkanfi and Dixit 2014, Yang, Zhao et al. 2015, Broz and Dixit 2016). In addition to canonical inflammasome activation, caspase-11 mediates non-canonical inflammasome activation in response to cytosolic LPS (Kayagaki, Warming et al. 2011).

Caspase-11 in mice or (caspase-4/5 in humans) belong to the family of inflammatory caspases and exhibits (46\%) similarity to caspase-1 (Faucheu, Diu et al. 1995, Kamens, Paskind et al. 1995, Munday, Vaillancourt et al. 1995, Faucheu, Blanchet et al. 1996, Wang, Miura et al. 1998, Lin, Choi et al. 2000, Lamkanfi, Declercq et al. 2002, Martinon and Tschopp 2004). It has been demonstrated that caspase-11-/ - but not caspase-1/- mice are resistant to septic shock mediated by injection of lethal doses of LPS (Kayagaki, Warming et al. 2011, Kayagaki, Wong et al. 2013). Caspase-11 expression is induced via multiple TLR stimulants and interferons (Kayagaki, Warming et al. 2011, Kayagaki, Wong et al. 2013). In this regard, extracellular LPS and cytokines primarily serve as a priming signal for expression of caspase11 and other inflammasome components. Furthermore, intracellular LPS triggers caspase-11-dependent inflammasome activation in the cytoplasm independently of TLR4 (Bauernfeind, Horvath et al. 2009, Kayagaki, Warming et al. 2011, Hagar, Powell et al. 2013, Kayagaki, Wong et al. 2013, Caution, Young et al. 2019).

In this study, we use caspase- $11^{-/-}$mice and HDM-mediated allergic inflammation model to delineate the role of caspase-11, in vivo. We also demonstrate that the inflammatory environment of asthma, specifically IL-4 and IL-13 cytokines, promote caspase-11 expression. Furthermore, caspase-11-/macrophages produce lower amounts of (KC, IL-6, and IL-12), and express lower levels of costimulatory molecules (e.g., CD40, CD86 and MHCII) in response to HDM stimulation. In vivo data show that HDM induce caspase-11 expression in WT mice. Furthermore, HDM promote differential inflammation and

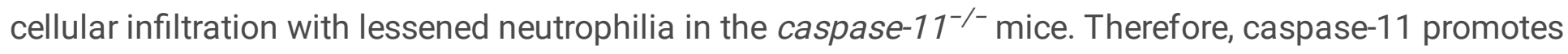
inflammation and neutrophil trafficking in response to HDM exposure.

\section{Results}

\section{HDM promote caspase-11 expression in macrophages derived from WT mice.}

House dust mites and their components (allergens, proteases, chitin, microbial LPS and ligands originating from mite-associated compounds) are activators of innate and adaptive immunity (Gregory 
and Lloyd 2011). Since caspase-11 is only expressed upon induction with pro-inflammatory stimuli (Schauvliege, Vanrobaeys et al. 2002), we tested whether HDM induce caspase-11 expression in vitro using primary bone marrow derived macrophages (BMDMs) from WT C57BL/6 mice. In contrast to freshly isolated lung macrophages, dendritic cells or epithelial cells, BMDMs are not activated or primed. Therefore their response will be directed only to HDM stimulation. The BMDM were treated with different concentrations of HDM for 4 or $24 \mathrm{~h}$, and caspase-11 expression was detected by Western blotting (Fig. 1A). Our data show that caspase-11 expression is induced $4 \mathrm{~h}$ post-HDM at all used concentrations, and stays active up to 24 hours post-treatment.

\section{Allergy-associated cytokines promote caspase-11 expression in macrophages derived from WT mice.}

Macrophages are classified into classically (M1) and alternatively activated macrophages (M2 or AAM), which reflect the T helper (Th1/Th2) subsets (Gordon 2003, Sica and Mantovani 2012). M1 macrophages promote inflammation, whereas M2 macrophages are critical for inflammation resolution (Awad, Assrawi et al. 2017). To determine if the inflammatory environment of asthma, and more specifically IL-4 and IL13 cytokines, promote caspase- 11 expression, we treated macrophages with IL-4 or IL-13 and examined caspase-11 expression by Western blotting. Our data demonstrate that macrophage treatment with IL-4 or IL-13 induces caspase-11 expression at 1, 4, 6 and $24 \mathrm{~h}$ post-treatment, similar to the treatment with other inflammatory stimuli like IL-1 $\beta$, LL-1 $a$ and LPS (Fig. 1B \& C).

We sought to identify the mediator of caspase-11 induction in response to IL-4 and IL-13 treatment. Caspase-11 is highly inducible with a 5 ' upstream regulatory promoter region comprised of multiple NFKB binding sites and one STAT binding site (Schauvliege, Vanrobaeys et al. 2002). Therefore, we tested if IL-4 or IL-13-induced expression of caspase-11 leads to STAT6 phosphorylation. Our data demonstrate that macrophages treatment with IL-4 and IL-13 induced phosphorylation of STAT6 in both WT and caspase-11 1/- (Fig. 1D \& E). Notably, STAT6 phosphorylation was not observed following treatment with IL-1 $\beta$ (Fig. 1D \& E). Similar total STAT6 was detected in all the samples (Fig. 1E). Therefore, the inflammatory environment of asthma, specifically IL-4 and IL-13 cytokines, induces caspase-11 expression and leads to STAT6 phosphorylation.

\section{Macrophages derived from caspase- $11^{-/-}$mice show reduced proinflammatory cytokine responses and reduced costimulatory molecule expression in response to HDM treatment.}

IL-1 $\beta$ is a pivotal cytokine in asthma pathogenesis. Thus, it plays a central role in HDM-mediated allergic inflammation (Jacquet 2011, Sundaram, Mitra et al. 2015), and its presence often designates the activation of the inflammasome (Kayagaki, Warming et al. 2011, Broz, Ruby et al. 2012, Gurung, Malireddi et al. 2012, Rathinam, Vanaja et al. 2012). Therefore, we determined the role of caspase-11 in the production of IL-1 $1 \beta$ by treating WT or caspase- $11^{-/-}$macrophages with $100 \mu \mathrm{g} / \mathrm{mL}$ of HDM. In contrast to

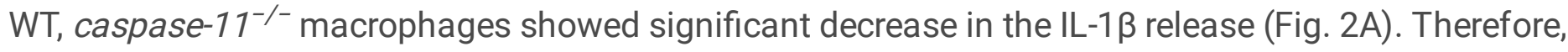
HDM induces caspase- 11 expression and increased IL-1 $\beta$ release in macrophages derived from WT mice. 
HDM elicit a strong immune response via promoting proinflammatory and anti-inflammatory cytokines. IL-4 is released and upregulated in asthma (Kay 2001, Dullaers, De Bruyne et al. 2012). Even though, HDM or IL-4 both induced caspase-11 expression, we hypothesized that caspase-11 response would be different in an environment containing the allergen only (which models the priming phase), or in asthmalike environment where both allergen and IL-4 are present (which represent the effector phase). To examine the role of caspase- 11 in response to these environments, we treated macrophages with HDM to model the priming phase or polarized BMDMs toward M2 by stimulating macrophages with IL-4 overnight followed by treatment with HDM + IL-4 for $24 \mathrm{~h}$, indicating the effector phase. Our data demonstrate that caspase- $11^{-/-}$macrophages release significantly less $\mathrm{KC}$, IL- 6 and IL-12 at $24 \mathrm{~h}$ postHDM treatment when compared to their WT counterparts (Fig. 2B, C, \& D). Treatment with IL-4 in the presence of HDM yield the same trend of responses with significant decrease in the levels of released KC, IL-6 and IL-12 following IL-4 treatment plus $100 \mu \mathrm{g} \mathrm{HDM}$ in caspase- $11^{-/-}$macrophages (Fig. 2B, C, \& D). In contrast to KC, treatment with IL-4 + HDM induced a significant increase in the level of IL- 6 at

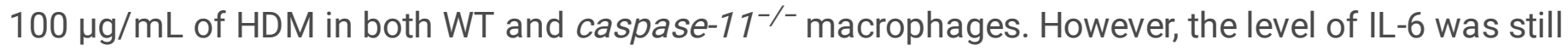

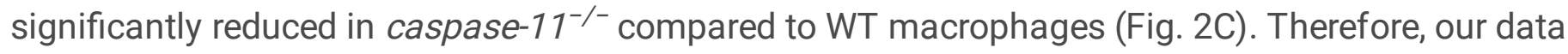
demonstrate reduced release of pro-inflammatory cytokines (KC, IL-6 and IL-12) from caspase-11 ${ }^{-/-}$ macrophages as compared to WT in response to HDM. Furthermore, when we simulated the allergic environment of asthma by treating cells with HDM and IL-4, caspase- $11^{-/-}$macrophages show reduced release of (KC, IL-6 and IL-12). Therefore, our data demonstrate reduced cytokines release by caspase$11^{-/-}$derived macrophages in an environment similar to asthma.

Macrophages are involved in antigen presentation to immune effector cells, providing two specific signals to achieve optimum activation of T cells (McAdam, Schweitzer et al. 1998). The CD28 and CD40L molecules on T cells are known to interact, respectively, with costimulatory-molecules CD80/CD86, and CD40 on antigen presenting cells (APCs) (Greenfield, Nguyen et al. 1998, Grewal and Flavell 1998). Therefore, we used flow cytometry to examine CD86 and CD40 expression, $24 \mathrm{~h}$ post-HDM, or post-HDM

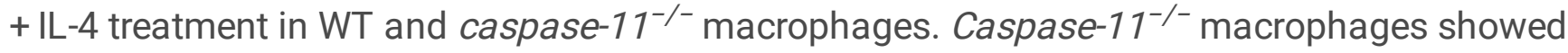
significantly reduced levels of CD86, CD40 and MHCII $24 \mathrm{~h}$ post-HDM + IL-4 stimulation (Fig. 2E \& F). In asthmatic animals, the M2 phenotype of macrophages is associated with high level of arginase-1 and family proteins chitinase-like Ym1 (Bhatia, Fei et al. 2011, Hong, Chung et al. 2014, Zhong, Yang et al.

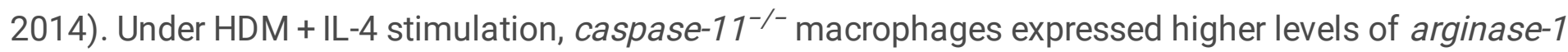
and $Y m 1$ but lower levels of the M1 marker $(\mathrm{CxCl10})$, when compared to macrophages treated with HDM

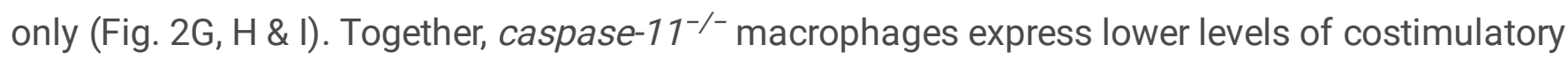
molecules and higher levels of arginase-1 and Ym1 associated with M2 phenotype.

\section{HDM sensitization and challenge promotes differential allergic inflammation and antibody responses in WT and caspase- $11^{-/-}$mice.}

Recently, an acute model of HDM-mediated experimental allergic lung inflammation was used to delineate the role of caspase-1 in asthma (Madouri, Guillou et al. 2015). However, mice used in these 
studies lack both caspase 1 and caspase 11 and thus, it is not clear if the phenotype observed is due to the lack of caspase-1, caspase-11, or both. Since we detected caspase-11 expression and differential release of inflammatory cytokines in response to HDM in vitro, we established a mouse model to study the role of caspase-11 in HDM-mediated inflammation. WT mice were sensitized with alum $+100 \mu \mathrm{g} \mathrm{HDM}$ on day 0 and 7 intra-peritoneally. Then mice were challenged with 13 doses of HDM intranasally $(25 \mu \mathrm{g})$. Control WT mice were mock sensitized and challenged with Phosphate-buffered saline (PBS) (Supplementary Fig. 1A). Optimization experiments were performed initially to determine the number of HDM challenges needed to provoke asthma symptoms. Self-isolation, low activity and drop in body temperature after each challenge were used as basic measurements to evaluate signs of allergy (Supplementary Fig. 1B). Our data show that HDM administration mediatesd successive and daily drop in body temperatures, which confirmed the validity of our model. Moreover, lungs derived from mice challenged with HDM showed an increase resistance to increasing concentrations of methacholine (Supplementary Fig. 1C). Allergy was evaluated by measuring total level of IgE in the serum and BAL fluid of WT mice. HDM-challenged mice show elevated level of total IgE in sera and BAL fluids as compared to the PBS control (Supplementary Fig. 1D \& E). Our results show a significant increase in the HDM-specific IgG1 and IgG2A isotypes in the serum (Supplementary Fig. 1F \& G). We further demonstrate that HDM induce caspase-11 expression in vivo in WT mice (Supplementary Fig. $1 \mathrm{H}$ ). Therefore, we successfully induced systemic and lung inflammation in HDM- sensitized and challenged WT mice.

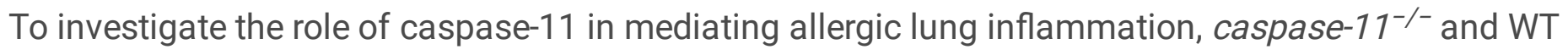
mice were sensitized with alum $+100 \mu \mathrm{g} \mathrm{HDM}$ on day 0 and 7 intra-peritoneally. Then, mice were

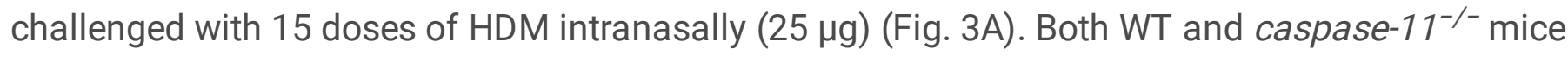

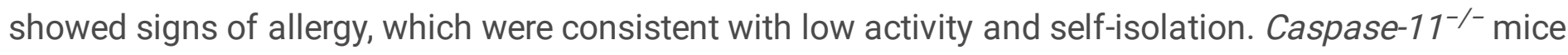
showed significantly higher drop in body temperature on challenges 9,13 and 14 as compared to WT mice. However, no significant difference was seen after challenge 15 which corresponds to day 35

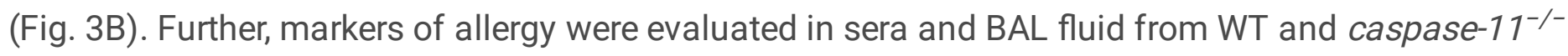
mice challenged with HDM. IgE antibody is normally present at low level in the plasma and is mainly produced by plasma cells in mucosal-associated lymphoid tissues. Atopic conditions, such as asthma, elevate serum levels of total IgE that drives the disease. Continuous exposure to HDM allergens lead to continuous production of HDM-specific IgE as well as continued maintenance of allergic inflammation in the airways (Wahn, Lau et al. 1997, Thomas, Hales et al. 2010). Therefore, we examined IgE levels in the

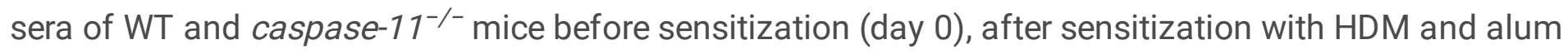
(day 14), day 28 , and $24 \mathrm{~h}$ after the last challenge (day 35 ). Our data show that sera and BAL fluid of WT and caspase-11 $11^{-1-}$ mice exhibit similar total IgE levels, (Fig. 3C, D). Furthermore, sera-derived from WT and caspase-11/-/- had similar levels of HDM-specific IgG1 on day 14, 28 and 35 (Fig. 3G). However, BAL fluid derived from caspase- $11^{-/-}$show significantly higher levels of total IgA on day 28 and 35 (Fig. 3F). There was no difference in HDM-specific IgA titers in the BAL fluid on day 35 (Fig. 3E). Our data

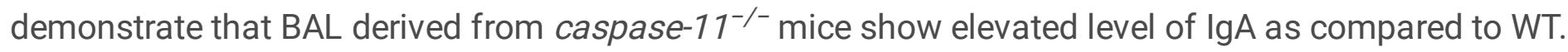
Nevertheless, no significant differences were seen in total IgE, lung functions or body temperature. 
Therefore, HDM promotes differential allergic inflammation and antibody responses in WT and caspase$11^{-/-}$mice.

\section{WT and caspase- $11^{-/-}$mice show differential cellular infiltration in their BAL fluid in response to HDM.}

Development of allergic responses requires activation of mast cells, basophils, and eosinophils (Wambre,

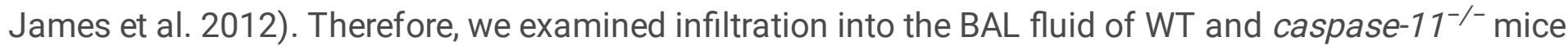
on day 35. Our data show a significant decrease in the total cellular infiltration into the BAL fluid of caspase-11/ $11^{-/}$mice compared to WT (Fig. 4A). Cells in the BAL fluid were immobilized on cytospin slides, fixed and stained to visualize specific cell populations. BAL from caspase-11 $11^{-/-}$mice show significant increase in the number of eosinophils (Fig. 4B). BAL fluids were also analyzed by flow cytometry. Our data demonstrate that caspase- $11^{-/-}$mice exhibit a significant increase in eosinophils $\left(\mathrm{CD}_{11} \mathrm{~b}^{+}\right.$SiglecF $\left.{ }^{+}\right)$, total $\mathrm{T}$ cells $\left(\mathrm{CD}^{+}\right)$, $\mathrm{T}$ helper cells $\left(\mathrm{CD} 3^{+} \mathrm{CD} 8^{-}\right)$(Fig. $\left.4 \mathrm{~F}, \mathrm{I} \& \mathrm{~K}\right)$. However, no significant difference was observed in myeloid cells $\left(\mathrm{CD} 11 \mathrm{~b}^{+}\right)$, alveolar macrophages $\left(\mathrm{CD} 11 \mathrm{C}^{+} \mathrm{F} 480^{+}\right)$, neutrophils $\left(\mathrm{CD} 11 \mathrm{~b}^{+} \mathrm{Ly} 6 \mathrm{G}^{+}\right)$, NK cells $\left(C D 49 b^{+}\right), B$ cells $\left(C D 19^{+}\right)$, cytotoxic T cells $\left(\mathrm{CD}^{+}{ }^{+} \mathrm{CD} 8^{+}\right)$and mast cells (Ckit ${ }^{+}$(Fig. 4C, D, E, G, H,

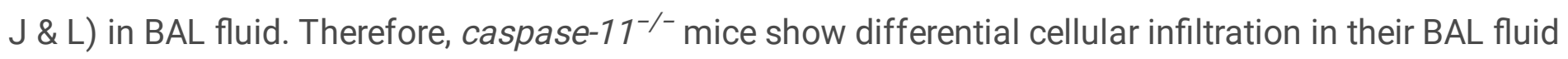
as compared to WT in response to HDM.

\section{Caspase- $11^{-/-}$mice show reduced histologic signs of lung inflammation but similar airway resistance and mucus production compared to WT mice.}

Asthma is often sustained by allergic sensitization, which leads to bronchial hyper-responsiveness and acute bronchoconstriction in response to specific and non-specific triggers. HDM cause bronchoconstriction in asthma patients and induce an inflammatory response in the lungs due to the

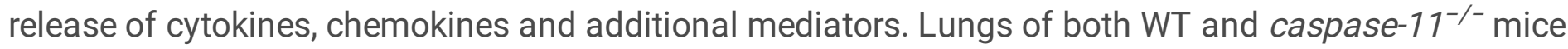
were similarly resistant to increasing concentrations of methacholine measured by Flexivent (Fig. 5A). To determine the effect of chronic HDM challenge on lung pathology in mice, lung tissues were collected $24 \mathrm{~h}$ after the last challenge. Lung sections were separately stained with H\&E and PAS. HDM challenge for 35 days caused significant reduction in inflammatory cell infiltration in caspase-11 ${ }^{-/-}$lungs as compared to WT but similar mucus production (Fig. 5B). Scored inflammation in lung sections shows that caspase- $11^{-/-}$lungs exhibit reduced neutrophils, macrophages and lymphocytes as compared to WT (Fig. 5C). Mucus hypersecretion was examined by measuring the expression level of muc5ac in lungs of

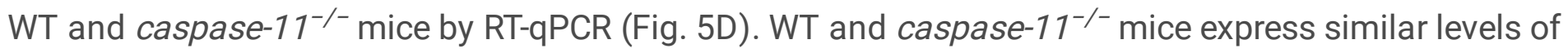
muc5ac in their lungs. These data demonstrate that caspase-11/-/- lungs show reduced infiltration of inflammatory cells into the lung tissue.

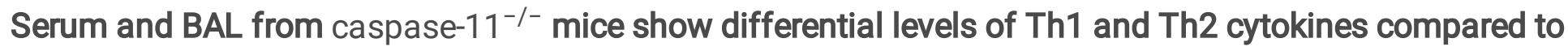
WT. 
HDM allergens initiate and sustain allergic inflammation. T cells play a role in the initiation and perpetuation of inflammation (Ricci, Rossi et al. 1993, Woodfolk 2007). In particular, Th2 cells have been identified as the cells involved in controlling immunoglobulin $\mathrm{E}$ ( $\operatorname{lgE}$ ) production because of their ability to produce IL-4 and IL-13 and influence function of eosinophils through the actions of IL-5 (Romagnani 2004). In atopic individuals, allergen-specific-Th2 cytokines, particularly IL-4, IL-5, IL-9, and IL-13, orchestrate and amplify the CD $4^{+}$Th2 response. In addition, Th2 and Th1 chemokines, including CCL11 and CXCL1, trigger the extravasation of and accumulation of eosinophils and neutrophils to perpetuate the allergic inflammation of the airways (Romagnani 2000, Zimmermann, Hershey et al. 2003). Furthermore, pro-inflammatory Th1 cytokines, such as IL-1 $\beta$, IL-1 $a$ and IL-6, exacerbate lung inflammation (Jacquet 2011, Jacquet 2011, Willart, Deswarte et al. 2012, Sundaram, Mitra et al. 2015). Selected cytokines (TGF- $\beta$, IL-17 and IL-10) are involved in tissue remodeling (Bergeron, Tulic et al. 2010).

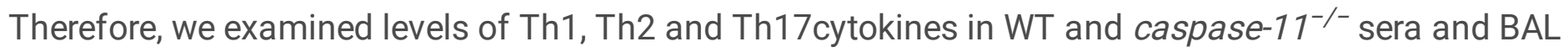
fluid samples. In the sera of HDM-treated mice, the levels of KC, TNFa and INFY were respectively reduced, higher and similar to WT (Fig. 6A, C \& E). However, the levels of these cytokines were reduced in the BAL

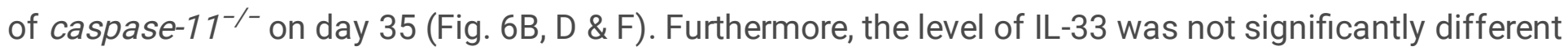

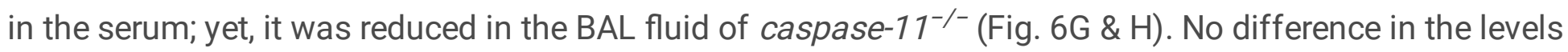
of serum IL-4, IL-5 and IL-10 (Fig. I, K \& 0) was observed between WT and caspase11-/- mice, while the levels of these cytokines were reduced in the BAL of caspase $11^{-/-}$mice (Fig. $6 \mathrm{~J}, \mathrm{~L} \& \mathrm{P}$ ). The level of IL-

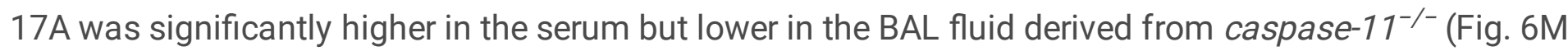
\& N). Importantly, we have tried to measure the levels of IL-13, IL-1 $\mathrm{a}$ and IL-1 $\beta$ by the multiplex. However, these cytokines were below the detection level of the multiplex. Therefore, our data show that caspase$11^{-/-}$mice exhibit a reduction in the level of Th1, Th2 and Th17 cytokines in BAL fluid.

\section{Discussion}

HDM is one of the most common aeroallergens, inducing sensitization in approximately $85 \%$ of patients with asthma (Gregory and Lloyd 2011), and playing a pivotal role in initiating and perpetuating lung inflammation in patients with asthma (Maunsell, Wraith et al. 1968, Roche, Chinet et al. 1997, Hatzivlassiou, Grainge et al. 2010). Clinically, there is a strong correlation between the level of HDM exposure and sensitization, which is a strong predictor for asthma (Birrell, Van Oosterhout et al. 2010, De Alba, Raemdonck et al. 2010). The activation of the inflammasome in the lung can be triggered by stimuli such as HDM in the asthmatic airway (Madouri, Guillou et al. 2015). However, the role of the

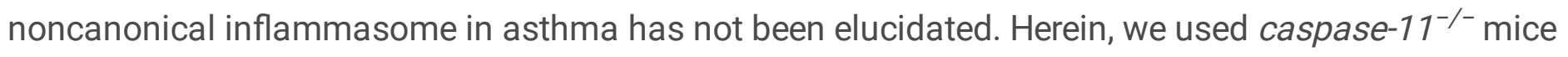
and macrophages from these mice to dissect whether caspase-11 plays a regulatory role in HDM induced allergic inflammation.

The study of macrophages in allergic asthma has focused on the role of alternatively activated AMs mediated by exposure to IL-4/IL-13. This macrophage subset positively correlated with the severity of airway inflammation in many studies (Draijer and Peters-Golden 2017). Adoptive transfer of in vitro differentiated IL-4/IL-13-stimulated macrophages into the lungs of allergic mice showed that these 
macrophages actively contribute to the exacerbation of the disease and are not just bystanders (Melgert, Oriss et al. 2010). These findings were later confirmed by a few other studies (Moreira, Cavassani et al. 2010, Kim, Park et al. 2011, Chung, Lee et al. 2016), showing that alternatively activated macrophage enhance the allergic inflammatory responses in lung tissue. Our data show that caspase-1 $11^{-/-}$ macrophages treated with IL-4 expresse more markers of M2 cells than WT. Ym1 is overexpressed in asthma and aggravates lung injury (Chupp, Lee et al. 2007, Moreira and Hogaboam 2011). Even though macrophages express a stronger M2 phenotype, caspase-11/-/- macrophages exhibit a significant reduction in expression of co-stimulatory molecules CD86, CD40 and MHCII $24 \mathrm{~h}$ post-treatment. Costimulation by macrophages is required to enhance the release of Th2 cytokines associated with asthma and B cells that will switch to IgE production. Our in vivo data show reduced IL-4 and other Th2 cytokines

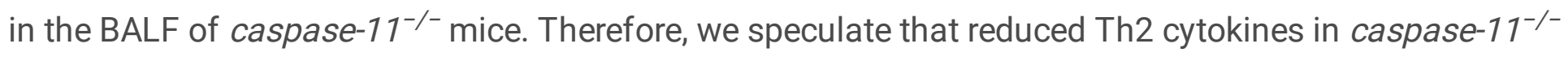
lungs is associated with reduced M2 phenotypes and asthma features.

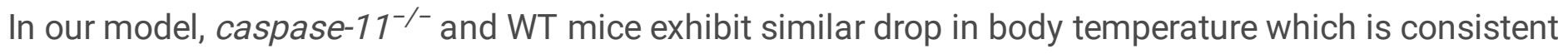

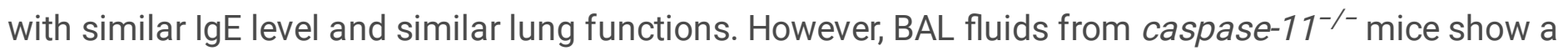
significant increase in eosinophils despite lower IL-5 level. It has been demonstrated that eotaxin (an important eosinophil-specific chemokine that is associated with the recruitment of eosinophils into sites of inflammation), can promote tissue eosinophilia independent of IL-5 (Mould, Matthaei et al. 1997). We

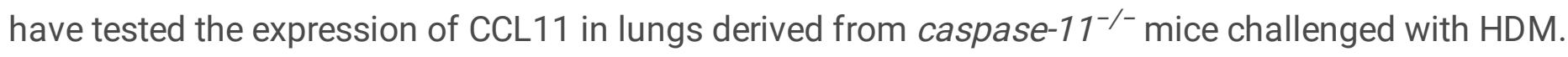

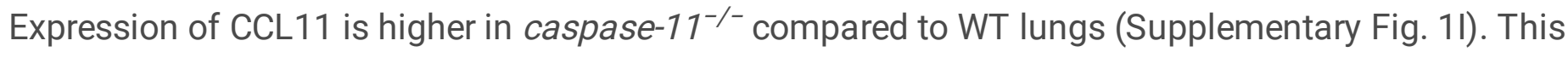
finding could explain the increase in eosinophils in caspase- $11^{-/-}$derived BAL fluid while IL-5 is reduced.

Additionally, caspase-11/-- mice exhibit reduced airway inflammation and reduced cellular infiltration including neutrophils, macrophages and lymphocytes in their lungs. The reduced infiltration of cells could be due to an inherent defect in their ability to migrate to sites of inflammation due to defects in the cytoskeleton (Li, Brieher et al. 2007, Caution, Young et al. 2019). We have shown that capase-11 neutrophils are defective in migration toward chemokines such as KC in vivo (Caution, Young et al. 2019). Furthermore, caspase-11 promotes neutrophil directional trafficking in an acute model of gout (Caution,

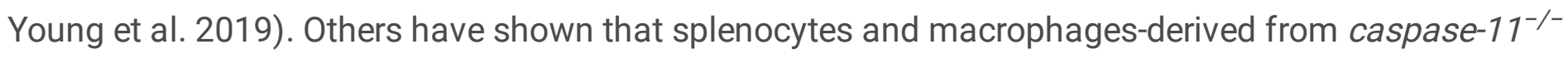
mice are defective in migration toward different chemokines in vitro and in vivo (Li, Brieher et al. 2007, Caution, Gavrilin et al. 2015). It was found that caspase- $11^{-/-}$T cells migrate less efficiently into lymphoid tissues (Bergsbaken and Bevan 2015). Modulation of actin polymerization by caspase-11 could regulate additional aspects of T cell biology, including T cell receptor (TCR) signaling (Ritter, Angus et al. 2013) and hence affect their ability to migrate.

Further, BAL fluids of caspase- $11^{-/-}$mice show increased total IgA. One other possibility for the reduced

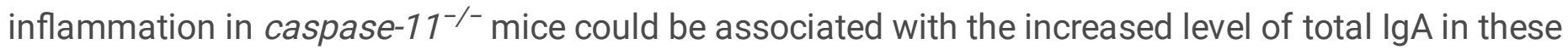
mice. In addition to inhibition of bacterial colonization and neutralizing viruses at mucosal surfaces, (Williams and Gibbons 1972, Boyaka 2017), slgA plays a protective role at mucosal surfaces by mediating tolerance and preventing hyper-inflammation toward allergens that can induce allergic 
inflammation, such as asthma (Balzar, Strand et al. 2006, Gloudemans, Lambrecht et al. 2013).

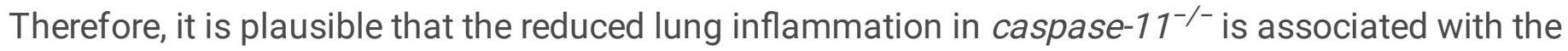
increased level of IgA, which could potentially limit binding of HDM to host cells in our experimental model.

The reduced inflammation in caspase-11/-/ lungs was evident by an overall reduction in KC, Th1 (TNFa

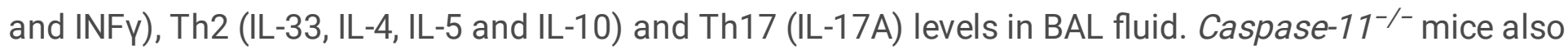
show reduced level of IL-17A, which is secreted by a distinct subset of $C D 4^{+} T$ helper cells and innate lymphoid cells (Yu, Kim et al. 2014). By secreting IL-17, Th17 cells orchestrate the recruitment of neutrophil granulocytes in the lungs and their activation directly through CXCL8 production (Pelletier, Maggi et al. 2010). Several reports have linked IL-17A production with asthma severity (Barczyk, Pierzchala et al. 2003, Sun, Zhou et al. 2005). Therefore, it is possible that the reduced number of

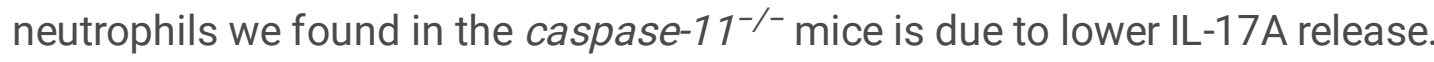

The level of Th2 cytokines is reduced in the BAL fluid of caspase $11^{\%-}$ mice. IL-33 is of particular importance since it is a chromatin-associated nuclear cytokine from the IL-1 family (Schmitz, Owyang et al. 2005). IL-33 is involved in polarization of T cells towards a Th2 phenotype and must be released extracellularly in order to bind to the ST2 receptor. Full length (FL) IL-33 is released passively during cell necrosis or when tissues are damaged, and functions as an alarmin (Cayrol and Girard 2009, Haraldsen, Balogh et al. 2009, Luthi, Cullen et al. 2009, Lefrancais, Roga et al. 2012, Cayrol and Girard 2014). While proteolysis of IL-33 by caspase-1 suppresses IL-33 bioactivity (Cayrol and Girard 2009, Luthi, Cullen et al. 2009, Talabot-Ayer, Lamacchia et al. 2009), inflammatory proteases including cathepsin $G$ and neutrophil elastase also cleave IL-33 full length (FL) into a shorter mature form with higher activity than IL-33FL (Lefrancais, Roga et al. 2012, Morita, Nakae et al. 2017).

It has been shown that caspase $-1 \%$ caspase $11^{\%}$ knockout mice exposed to HDM exhibit enhanced lung inflammation associated with a marked eosinophil recruitment, increased expression of IL-4, IL-5, IL-13, as well as full-length and cleaved bioactive IL-33 (Madouri, Guillou et al. 2015). In our caspase-11/mouse model, we detected less IL-33 in their BAL fluid and less Th2 cytokines associated with reduced inflammation. Given the role of IL-33 in enhancing Th2 cytokines production, we have seen reduced IL-5, IL-4 and IL-10. The reduction of Th2 cytokines could be a consequence of the reduced IL-33 in the BAL fluid.

On the inflammasome side, it is possible that caspase- 1 is activated in vivo in the absence of caspase- 11 . We have seen a reduction in IL-1 $\beta$ level in caspase $-11 \%$ macrophages treated with HDM in vitro. However, IL-1 $\beta$ level in WT and caspase-11\% BAL fluid derived from mice challenged with HDM on day 35 were below the detection of the multiplex. Being a pro-inflammatory cytokine, it is possible that IL-1 $\beta$ level is more important at earlier time points in our model.

Even though we do not have a direct mechanism by which caspase-11 regulates airway inflammation in response to HDM, we speculate that lungs of caspase- $11 \%$ mice exhibit global reduction in inflammation 
seen by reduced chemokines, Th1, Th2 and Th17 cells. This reduction could impact cells recruitment into the lungs of these mice in response to HDM. Intriguingly, a new paper was published by Zaslona et al. on the role of caspase- $11^{\%}$ in response to ova and alum. The authors demonstrated that caspase- $11 \%$ mice show reduction in Th1, Th2 and Th17 cytokines in response to ova and alum (Zaslona, Flis et al. 2020). Even though we used a different allergen, exposure time and routes of administration, the Zaslona findings are in line with our data. Macrophages and dendritic cells experience the allergen early on and present processed fragments to naïve $T$ cells. Following activation, $T$ cells release cytokines that polarize immune cells and skew the environment toward asthma. It is possible that macrophages and dendritic cells show reduced ability to present the allergen to naïve T cells in vivo, which results in an overall reduction of cytokines and chemokines involved in cells polarization as well as the disease progression.

In conclusion, caspase-11 regulates lung inflammation in response to HDM during the priming and the effector phases of asthma. Our study offers several intriguing scenarios for the diverse functions of caspase-11. Expression of caspase-11 in innate immune cells following HDM exposure maybe required for the antigen presentation by macrophages and dendritic cells to naïve T cells. Subsequently, insufficient antigen presentation leads to reduction in cytokines and chemokines released in the BAL fluids. We have shown that caspase-11 regulates autophagy, which is an essential process for antigen presentation by immune cells\{Krause, $2018 \# 733\}$. Our published work and that of others also support the notion for inherent defect in migration of caspase $11 \%$ cells due to defect in the actin cytoskeleton ( $\mathrm{Li}$, Brieher et al. 2007, Caution, Young et al. 2019). Further studies will explore these possibilities.

\section{Materials And Methods}

\section{Mice}

C57BL/6 WT mice were obtained from The Jackson Laboratory (Bar Harbor, ME, USA). The caspase-1 1\% mice were generously provided by Dr. Junying Yuan. (Harvard Medical School, Boston, MA, USA) (Wang, Miura et al. 1998). All mice are in the C57BL/6 background. All mice were housed in a pathogen-free facility and experiments were conducted with approval from the Animal Care and Use Committee at The Ohio State University (Columbus, $\mathrm{OH}, \mathrm{USA}$ ) in accordance with $\mathrm{NIH}$ and OSU IACUC guidelines. Mice were maintained in a temperature-controlled $(23 \otimes \mathrm{C})$ facility with a strict 12 -h light/ dark cycle and were given free access to food and water.

\section{Cell culture and treatment of BMDMs with HDM and inflammatory stimuli}

BMDMs from WT or caspase-11/- were derived from the femurs of five to eight-week-old mice as previously described (Abu Khweek, Fernandez Davila et al. 2013, Khweek, Caution et al. 2013), and grown in IMDM (Iscove's modified Dulbecco's medium) supplemented with L929 fibroblast cell line (ATCC)cultured supernatant and 10\% heat inactivated fetal bovine serum (HIFBS) (Gibco). Cultivated macrophages were washed twice with PBS and incubated in IMDM media during treatments. Caspase-11 induction was measured by treating WT macrophages with various inflammatory mediators including IL- 
1a (R\&D Systems, 400-ML-005). (20ng/mL), IL-1ß (20ng/mL) (R\&D Systems, 401-ML-005), LPS (100ng/mL) (tlrl-eklps) for $4 \mathrm{~h}$. WT macrophages were stimulated with IL-4 $(5 \mathrm{ng} / \mathrm{mL})$ or IL-13 $(20 \mathrm{ng} / \mathrm{mL})$ (PeproTech, 214-14, 210-13) for 1,4,6 and $24 \mathrm{~h}$ in IMDM media. In some instances, macrophages were pre-treated with IL-4 overnight, and then macrophages were un-treated or treated with HDM, HDM+ IL-4 for 4 or $24 \mathrm{~h}$ (Stallergenes Greer, XPB82D3A2.5). The vial was suspended with phosphate buffer saline to obtain $10 \mathrm{mg} / \mathrm{ml}$ stock, then $10 \mu \mathrm{l}$ of the stock was used for each mouse which included $\sim 7.85 \mathrm{ng}$ of endotoxin.

\section{Induction of HDM-mediated allergic airway inflammation}

To induce HDM-driven airway inflammation, mice were injected with HDM $(100 \mu \mathrm{g})$ adsorbed with alum (Imject ${ }^{\mathrm{TM}}$ Alum, Thermo Scientific 77161) intraperitoneally on day 0 and day 7. Isoflurane anesthetized mice were challenged with $(25 \mu \mathrm{g})$ HDM intranasally for 15 challenges from day 14 until day 35 . Twentyfour hours after the last challenge, mice were sacrificed for bronchoalveolar lavage (BAL), bronchial hyperresponsiveness, cytokines and chemokines concentration, histology and quantitative real time PCR.

\section{Assessment of surface body temperature}

Body temperature was assessed by measuring surface body temperature with the aid of infrared thermometers [Heat spy infrared thermal imaging camera (Wahl, Culver City, CA, USA)]. Mice were incubated for 10 minutes at room temperature, and then their body temperatures were measured. Subsequently, mice were challenged with HDM and incubated for 30 minutes, and their body temperatures were measured again. Then, the body temperature after the challenge was subtracted from that before the challenge for each mouse. This is shown as drop in body temperature as indicated in the figures.

\section{Determination of bronchial hyper-responsiveness}

Lung function (respiratory system resistance) was assessed using the forced-oscillation technique (Irvin and Bates 2003). Briefly, mice were sedated via intra-peritoneal injection of diazepam/Valium (70 $\mathrm{\mu l}$ ). Ten minutes after, ketamine was administered via intra-peritoneal injection according to mice weight. For instance, mice weighed above or below $25 \mathrm{~g}$ were given $90 \mu \mathrm{l}$ or $70 \mu \mathrm{l}$ of ketamine, respectively. Mice were paralyzed by intra-muscular injections of rocuronium and intubated with an 18-gauge catheter. Anesthetized mice were mechanically ventilated on a flexiVent computer-controlled piston ventilator (SClreq, Montreal, PC, Canada) with $8 \mathrm{ml} / \mathrm{kg}$ tidal volume at a frequency of 150 breaths/min against 2-3 $\mathrm{cmH} 2 \mathrm{O}$ positive end-expiratory pressure (Irvin and Bates 2003). Airway responsiveness to bronchoconstrictors was measured following exposure to increasing concentrations of methacholine (0.1-50 mg/ml) (Davis, Xu et al. 2007).

\section{Bronchoalveolar lavage (BAL) and flow cytometry of lung mononuclear cells}


Bronchoalveolar lavage was performed by washing the lungs once with $0.8 \mathrm{ml}$ of saline solution at room

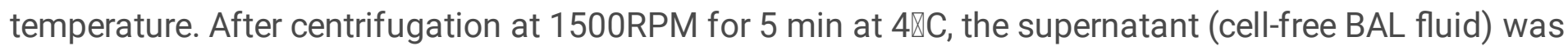
stored at $-20 \llbracket C$ for cytokine analysis. To determine the percentages of inflammatory cells infiltration in BAL fluid, cells were suspended in FACS buffer and either unstained or single/ multiple stained with the following antibodies: anti CD3 (T-cells), anti CD8 (cytotoxic T cells), anti CD19 (B cells), anti C-kit (mast cells), anti SiglecF (eosinophils), anti CD49b (NK-cells) and anti CD11c/F480 (alveolar macrophages). Stained cells were analyzed with an Attune NxT flow cytometer (Thermo Fisher Scientific, Waltham, MA).

\section{Assessment of HDM-specific IgG1 and IgA Ab responses and total IgA Levels}

Total and HDM-specific Ab responses were measured in sera and BALF by enzyme-linked immunosorbent assay (ELISA). Briefly, microtiter plates were coated with HDM $(25 \mu \mathrm{g} / \mathrm{ml})$. For detection of HDM-specific IgG1 and IgA Abs, serial dilutions of serum or BALFs were added to the plates and the binding antibodies were detected with HRP-conjugated antisera (Southern Biotech Associates Inc., Birmingham, AL, USA). Biotin-conjugated rat anti-mouse IgG1 monoclonal Abs and HRP-conjugated streptavidin (BD Bioscience, San Jose, CA, ISA) were used to measure $\lg \mathrm{G} 1$. The Ab titers were determined as the last dilutions of samples that with an absorbance of $>0.1$ above that of control samples. Total IgA levels were determined by ELISA using extrapolation against IgA standards (Duverger, Jackson et al. 2006).

\section{Total IgE quantification}

Total IgE Ab levels were determined by a mouse IgE ELISA kit (Thermofischer scientific). Sample dilution and IgE detection were done according to instructions from the manufacturer.

\section{Real-Time PCR}

Tissues were collected; snap frozen, and reduced to powder before adding TRIzol (Invitrogen, Carlsbad, CA, USA). RNA was isolated and CDNA was synthesized by using Superscript III (Invitrogen) and real-time PCR was performed as previously described (Gavrilin, Bouakl et al. 2006, Abu Khweek, Kanneganti et al. 2016) with the aid of specific primers. The gene of interest $\mathrm{Ct}$ was normalized to $\beta$-actin $\mathrm{Ct}$ and expressed as relative copy number $(\mathrm{RCN})$ of mRNA expression $\left(\mathrm{RCN}=2^{-\Delta \mathrm{Ct}}\right)$.

\section{Lung Histology}

The right lungs from each group ( $n=5$ per group) were fixated with $4 \%$ buffered formalin solution. Sections were stained with hematoxylin and eosin (H\&E) for quantifying inflammation and PAS (Periodic Acid Schiff, Sigma-Aldrich) for quantifying mucus producing goblet cells. Sectioning, staining and scoring were performed at the Ohio state veterinary school. Several parameters were evaluated including perivesicular, peribronchiolar and parenchymal inflammation, inflammatory cells in blood vessel walls,

perivascular and peribronchiolar edema, alveolar macrophages distant to affected airways/blood vessels, predominance of neutrophils and goblet cell mucus in bronchioles. Scoring scale was (0-5) where, 0 , $1,2,3,4$ and 5 represents no signs, mild (<25\%), moderate (26-50\%), marked (51-75\%), Severe $(>75 \%)$, and 
maximum inflammation. The semi-quantitative scoring rubric used to produce our data was developed and modified by board-certified comparative veterinary pathologist, Dr. Kara N. Corps, DVM, PhD, DACVP, at the Comparative Pathology and Mouse Phenotyping Shared Resource of The Ohio State University. Dr. Corps produced the scoring system based on the requirements of our project and employing standard semi-quantitative methods. The included manuscripts are examples from our field of similar methods and were referenced by Dr. Corps in developing our standardized method, which was used for all semiquantitative histopathology scoring data reported in this manuscript (Clarke, Davis et al. 2014, Anas, Yang et al. 2017).

\section{Western blotting}

Protein extraction from macrophages was performed using TRIzol ${ }^{\mathrm{TM}}$ reagent according to the manufacturer's instructions (Invitrogen, Carlsbad, CA, USA). Briefly, after phase separation using chloroform, $100 \%$ ethanol was added to the interphase/phenol-chloroform layer to precipitate genomic DNA. Subsequently, the phenol-ethanol supernatant was mixed with isopropanol in order to precipitate out proteins. Isolated protein was then denatured in a urea-based lysis buffer. The Bradford method was used to determine protein concentrations. Equal amounts of protein were separated by $12 \%$ SDSpolyacrylamide gel (Biorad, 161-0158) and transferred to a polyvinylidene fluoride (PVDF) membrane (Biorad, 162-0177). Membranes were immunoblotted with antibodies that recognize caspase-11 (Sigma Aldrich, C1354), GAPDH (Cell Signaling Technology, 2118), Phospho-Stat6 (Tyr641) (D8S9Y) (Cell Signaling Technology, 56554), total Stat6 D3H4 (Cell Signaling Technology, 5394). Corresponding secondary antibodies conjugated with horseradish peroxidase (Cell Signaling Technology, 7074; Santa Cruz Biotechnology, sc-2006) and in combination with enhanced chemiluminescence reagent (Amersham, RPN2209,) were used to visualize protein bands

\section{Cytokine measurements}

Cytokines including IL-1 $\beta, \mathrm{KC}$, TNFa, IL-4, IL-5, IL-13, IL-10, INFY and IL-33, were measured in serum and BAL fluid samples using multiplex ELISA according to the manufacturer recommendations at the center for Clinical and Translational Science (CCTS) at Ohio State University. The level of IL-1 13 , IL-6, IL-12 and $\mathrm{KC}$ in the supernatant of treated macrophages was determined by specific sandwich ELISA following the manufacturer's protocol (R\&D) system Inc.

\section{Statistical analysis}

Figures display the mean and standard deviation (SD) as indicated in the figure legends. Comparisons between groups were conducted by multiple t-test, two-way ANOVA or linear mixed effects models were used for analysis to take account of the correlation among observations from the same animal within the same cage. Holm's procedure was used to adjust for multiple comparisons or multiple outcomes to control for type I error at 0.05. Mice were age and sex matched, however no difference was seen in the gender. We did two independent in vivo experiments with seven and five mice per group, respectively which lead to similar results. The numbers of animal/group are indicated for each statistical analysis and 
this is indicated in the figure legends. Statistically significant differences were defined as ${ }^{*} \mathrm{P}<0.05,{ }^{\star *} \mathrm{P}<$ 0.01 , and ${ }^{* * *} \mathrm{P}<0.001$.

\section{Declarations}

\section{Ethics Statement}

The animal study was reviewed and approved by OSU IACUC.

\section{Competing Interest}

The authors declare that the research was conducted in the absence of any commercial or financial relationships that could be construed as a potential conflict of interest.

\section{Availability of data and materials}

All the obtained data are available in the laboratory of Dr. Amal Amer and Dr. Prosper N Boyaka.

\section{Funding}

Studies in the Amer laboratory are supported by NIAID R01 Al24121 and NHLBI R01 HL127651-01A1. Studies in the Boyaka laboratory are supported by NIH grant R01DK101323 and R01Al145144. AAK was supported by Taawon Welfare Association, West Bank, Palestine and Bank of Palestine. KK was supported by a Cystic Fibrosis Foundation Post-doctoral Research Fellowship and by Deutsche Forschungsgemeinschaft (DFG-German Research Foundation). KH is supported by a Cure Cystic Fibrosis Columbus Training grant. $A B$ and $S E$ are supported by funding from the Egyptian Bureau of Higher Education.

\section{Author Contributions}

AAK designed, performed analyzed, interpreted data and wrote, edited, and reviewed the manuscript. MRJ assisted in performing in vivo experiments. $\mathrm{EK}, \mathrm{ZA}, \mathrm{KK}, \mathrm{KD}, \mathrm{SE}, \mathrm{KH}, \mathrm{AB}$ and MAG contributed by performing experiments and editing the manuscript. PNB helped in designing, conceptualizing experiments, interpreting data, editing and reviewing the manuscript. XZ performed statistical analysis. AOA assisted in the experimental design and implementation, interpretation of data, as well as editing the manuscript.

\section{Acknowledgements}

We thank Dr. Kara Corps at the College of Veterinary Medicine/Department of Veterinary Biosciences at the Ohio State University, Columbus $\mathrm{OH}$, USA, for the histological evaluation of lung tissue. Cytokine analysis using the V-PLEX Proinflammatory Panel 1 (mouse) Kit with modification was supported by Award Number Grant from the National Center for Advancing Translational Sciences. We thank Dr. lan 
Davis at the Department of Veterinary Biosciences at the Ohio State University for using the Flexivent machine.

\section{References}

Abu Khweek, A., N. S. Fernandez Davila, K. Caution, A. Akhter, B. A. Abdulrahman, M. Tazi, H. Hassan, L. A. Novotny, L. O. Bakaletz and A. O. Amer (2013). "Biofilm-derived Legionella pneumophila evades the innate immune response in macrophages." Front Cell Infect Microbiol 3: 18.

Abu Khweek, A., A. Kanneganti, D. D. Guttridge and A. O. Amer (2016). "The Sphingosine-1-Phosphate Lyase (LegS2) Contributes to the Restriction of Legionella pneumophila in Murine Macrophages." PLoS One 11(1): e0146410.

Anas, A. A., J. Yang, J. Daan de Boer, J. J. Roelofs, B. Hou, A. F. de Vos and T. van der Poll (2017). "General, but not myeloid or type II lung epithelial cell, myeloid differentiation factor 88 deficiency abrogates house dust mite induced allergic lung inflammation." Clin Exp Immunol 187(2): 204-212.

Arlian, L. G. and T. A. Platts-Mills (2001). "The biology of dust mites and the remediation of mite allergens in allergic disease." J Allergy Clin Immunol 107(3 Suppl): S406-413.

Asokananthan, N., P. T. Graham, D. J. Stewart, A. J. Bakker, K. A. Eidne, P. J. Thompson and G. A. Stewart (2002). "House dust mite allergens induce proinflammatory cytokines from respiratory epithelial cells: the cysteine protease allergen, Der $\mathrm{p} 1$, activates protease-activated receptor (PAR)-2 and inactivates PAR-1." $\underline{\mathrm{J}}$ Immunol 169(8): 4572-4578.

Awad, F., E. Assrawi, C. Jumeau, S. Georgin-Lavialle, L. Cobret, P. Duquesnoy, W. Piterboth, L. Thomas, K. Stankovic-Stojanovic, C. Louvrier, I. Giurgea, G. Grateau, S. Amselem and S. A. Karabina (2017). "Impact of human monocyte and macrophage polarization on NLR expression and NLRP3 inflammasome activation." PLoS One 12(4): e0175336.

Balzar, S., M. Strand, T. Nakano and S. E. Wenzel (2006). "Subtle immunodeficiency in severe asthma: IgA and IgG2 correlate with lung function and symptoms." Int Arch Allergy Immunol 140(2): 96-102.

Barczyk, A., W. Pierzchala and E. Sozanska (2003). "Interleukin-17 in sputum correlates with airway hyperresponsiveness to methacholine." Respir Med 97(6): 726-733.

Bauernfeind, F. G., G. Horvath, A. Stutz, E. S. Alnemri, K. MacDonald, D. Speert, T. Fernandes-Alnemri, J. Wu, B. G. Monks, K. A. Fitzgerald, V. Hornung and E. Latz (2009). "Cutting edge: NF-kappaB activating pattern recognition and cytokine receptors license NLRP3 inflammasome activation by regulating NLRP3 expression." J Immunol 183(2): 787-791.

Bergeron, C., M. K. Tulic and Q. Hamid (2010). "Airway remodelling in asthma: from benchside to clinical practice." Can Respir J 17(4): e85-93. 
Bergsbaken, T. and M. J. Bevan (2015). "Cutting Edge: Caspase-11 Limits the Response of CD8+ T Cells to Low-Abundance and Low-Affinity Antigens." J Immunol 195(1): 41-45.

Bhatia, S., M. Fei, M. Yarlagadda, Z. Qi, S. Akira, S. Saijo, Y. Iwakura, N. van Rooijen, G. A. Gibson, C. M. St Croix, A. Ray and P. Ray (2011). "Rapid host defense against Aspergillus fumigatus involves alveolar macrophages with a predominance of alternatively activated phenotype." PLoS One 6(1): e15943.

Birrell, M. A., A. J. Van Oosterhout and M. G. Belvisi (2010). "Do the current house dust mite-driven models really mimic allergic asthma?" Eur Respir J 36(5): 1220-1221.

Bordas-Le Floch, V., M. Le Mignon, L. Bussieres, K. Jain, A. Martelet, V. Baron-Bodo, E. Nony, L. Mascarell and P. Moingeon (2017). "A combined transcriptome and proteome analysis extends the allergome of house dust mite Dermatophagoides species." PLoS One 12(10): e0185830.

Boyaka, P. N. (2017). "Inducing Mucosal IgA: A Challenge for Vaccine Adjuvants and Delivery Systems." $\underline{J}$ Immunol 199(1): 9-16.

Broz, P. and V. M. Dixit (2016). "Inflammasomes: mechanism of assembly, regulation and signalling." Nat Rev Immunol 16(7): 407-420.

Broz, P., T. Ruby, K. Belhocine, D. M. Bouley, N. Kayagaki, V. M. Dixit and D. M. Monack (2012). "Caspase11 increases susceptibility to Salmonella infection in the absence of caspase-1." Nature 490(7419): 288291.

Calderon, M. A., A. Linneberg, J. Kleine-Tebbe, F. De Blay, D. Hernandez Fernandez de Rojas, J. C. Virchow and P. Demoly (2015). "Respiratory allergy caused by house dust mites: What do we really know?" $\underline{J}$ Allergy Clin Immunol 136(1): 38-48.

Caution, K., M. A. Gavrilin, M. Tazi, A. Kanneganti, D. Layman, S. Hoque, K. Krause and A. O. Amer (2015). "Caspase-11 and caspase-1 differentially modulate actin polymerization via RhoA and Slingshot proteins to promote bacterial clearance." Sci Rep 5: 18479.

Caution, K., N. Young, F. Robledo-Avila, K. Krause, A. Abu Khweek, K. Hamilton, A. Badr, A. Vaidya, K. Daily, H. Gosu, M. N. K. Anne, M. Eltobgy, D. Dakhlallah, S. Argwal, S. Estfanous, X. Zhang, S. Partida-Sanchez, M. A. Gavrilin, W. N. Jarjour and A. O. Amer (2019). "Caspase-11 Mediates Neutrophil Chemotaxis and Extracellular Trap Formation During Acute Gouty Arthritis Through Alteration of Cofilin Phosphorylation." Front Immunol 10: 2519.

Cayrol, C. and J. P. Girard (2009). "The IL-1-like cytokine IL-33 is inactivated after maturation by caspase1." Proc Natl Acad Sci U S A 106(22): 9021-9026.

Cayrol, C. and J. P. Girard (2014). "IL-33: an alarmin cytokine with crucial roles in innate immunity, inflammation and allergy." Curr Opin Immunol 31: 31-37. 
Chung, S., T. J. Lee, B. F. Reader, J. Y. Kim, Y. G. Lee, G. Y. Park, M. Karpurapu, M. N. Ballinger, F. Qian, L. Rusu, H. Y. Chung, T. G. Unterman, C. M. Croce and J. W. Christman (2016). "FoxO1 regulates allergic asthmatic inflammation through regulating polarization of the macrophage inflammatory phenotype." Oncotarget 7(14): 17532-17546.

Chupp, G. L., C. G. Lee, N. Jarjour, Y. M. Shim, C. T. Holm, S. He, J. D. Dziura, J. Reed, A. J. Coyle, P. Kiener, M. Cullen, M. Grandsaigne, M. C. Dombret, M. Aubier, M. Pretolani and J. A. Elias (2007). "A chitinase-like protein in the lung and circulation of patients with severe asthma." N Engl J Med 357(20): 2016-2027.

Clarke, D. L., N. H. Davis, C. L. Campion, M. L. Foster, S. C. Heasman, A. R. Lewis, I. K. Anderson, D. J. Corkill, M. A. Sleeman, R. D. May and M. J. Robinson (2014). "Dectin-2 sensing of house dust mite is critical for the initiation of airway inflammation." Mucosal Immunol 7(3): 558-567.

Davis, I. C., A. Xu, Z. Gao, J. M. Hickman-Davis, P. Factor, W. M. Sullender and S. Matalon (2007).

"Respiratory syncytial virus induces insensitivity to beta-adrenergic agonists in mouse lung epithelium in vivo." Am J Physiol Lung Cell Mol Physiol 293(2): L281-289.

De Alba, J., K. Raemdonck, A. Dekkak, M. Collins, S. Wong, A. T. Nials, R. G. Knowles, M. G. Belvisi and M. A. Birrell (2010). "House dust mite induces direct airway inflammation in vivo: implications for future disease therapy?" Eur Respir J 35(6): 1377-1387.

Draijer, C. and M. Peters-Golden (2017). "Alveolar Macrophages in Allergic Asthma: the Forgotten Cell Awakes." Curr Allergy_Asthma Rep 17(2): 12.

Dullaers, M., R. De Bruyne, F. Ramadani, H. J. Gould, P. Gevaert and B. N. Lambrecht (2012). "The who, where, and when of IgE in allergic airway disease." J Allergy Clin Immunol 129(3): 635-645.

Duverger, A., R. J. Jackson, F. W. van Ginkel, R. Fischer, A. Tafaro, S. H. Leppla, K. Fujihashi, H. Kiyono, J. R. McGhee and P. N. Boyaka (2006). "Bacillus anthracis edema toxin acts as an adjuvant for mucosal immune responses to nasally administered vaccine antigens." J Immunol 176(3): 1776-1783.

Faucheu, C., A. M. Blanchet, V. Collard-Dutilleul, J. L. Lalanne and A. Diu-Hercend (1996). "Identification of a cysteine protease closely related to interleukin-1 beta-converting enzyme." Eur J Biochem 236(1): 207213.

Faucheu, C., A. Diu, A. W. Chan, A. M. Blanchet, C. Miossec, F. Herve, V. Collard-Dutilleul, Y. Gu, R. A. Aldape, J. A. Lippke and et al. (1995). "A novel human protease similar to the interleukin-1 beta converting enzyme induces apoptosis in transfected cells." EMBO J 14(9): 1914-1922.

Gavrilin, M. A., I. J. Bouakl, N. L. Knatz, M. D. Duncan, M. W. Hall, J. S. Gunn and M. D. Wewers (2006). "Internalization and phagosome escape required for Francisella to induce human monocyte IL-1beta processing and release." Proc Natl Acad Sci U S A 103(1): 141-146. 
Gloudemans, A. K., B. N. Lambrecht and H. H. Smits (2013). "Potential of immunoglobulin A to prevent allergic asthma." Clin Dev Immunol 2013: 542091.

Gordon, S. (2003). "Alternative activation of macrophages." Nat Rev Immunol 3(1): 23-35.

Greenfield, E. A., K. A. Nguyen and V. K. Kuchroo (1998). "CD28/B7 costimulation: a review." Immunol 18(5): 389-418.

Gregory, L. G. and C. M. Lloyd (2011). "Orchestrating house dust mite-associated allergy in the lung." Trends Immunol 32(9): 402-411.

Grewal, I. S. and R. A. Flavell (1998). "CD40 and CD154 in cell-mediated immunity." Annu Rev Immunol 16: 111-135.

Gurung, P., R. K. Malireddi, P. K. Anand, D. Demon, L. Vande Walle, Z. Liu, P. Vogel, M. Lamkanfi and T. D. Kanneganti (2012). "Toll or interleukin-1 receptor (TIR) domain-containing adaptor inducing interferonbeta (TRIF)-mediated caspase-11 protease production integrates Toll-like receptor 4 (TLR4) protein- and Nlrp3 inflammasome-mediated host defense against enteropathogens." J Biol Chem 287(41): 3447434483.

Hagar, J. A., D. A. Powell, Y. Aachoui, R. K. Ernst and E. A. Miao (2013). "Cytoplasmic LPS activates caspase-11: implications in TLR4-independent endotoxic shock." Science 341(6151): 1250-1253.

Hammad, H., M. Chieppa, F. Perros, M. A. Willart, R. N. Germain and B. N. Lambrecht (2009). "House dust

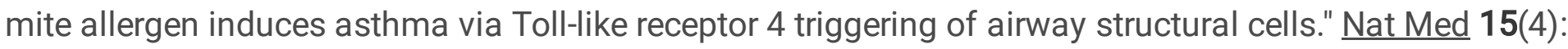
410-416.

Haraldsen, G., J. Balogh, J. Pollheimer, J. Sponheim and A. M. Kuchler (2009). "Interleukin-33 - cytokine of dual function or novel alarmin?" Trends Immunol 30(5): 227-233.

Hatzivlassiou, M., C. Grainge, V. Kehagia, L. Lau and P. H. Howarth (2010). "The allergen specificity of the late asthmatic reaction." Allergy 65(3): 355-358.

Hong, J. Y., Y. Chung, J. Steenrod, Q. Chen, J. Lei, A. T. Comstock, A. M. Goldsmith, J. K. Bentley, U. S. Sajjan and M. B. Hershenson (2014). "Macrophage activation state determines the response to rhinovirus infection in a mouse model of allergic asthma." Respir Res 15: 63.

Irvin, C. G. and J. H. Bates (2003). "Measuring the lung function in the mouse: the challenge of size." Respir Res 4: 4.

Jacquet, A. (2011). "The role of innate immunity activation in house dust mite allergy." Trends Mol Med 17(10): 604-611. 
Jacquet, A. (2011). "The role of the house dust mite-induced innate immunity in development of allergic response." Int Arch Allergy Immunol 155(2): 95-105.

Janeway, C. A., Jr. and R. Medzhitov (2002). "Innate immune recognition." Annu Rev Immunol 20: 197216.

Kamens, J., M. Paskind, M. Hugunin, R. V. Talanian, H. Allen, D. Banach, N. Bump, M. Hackett, C. G. Johnston, P. Li and et al. (1995). "Identification and characterization of ICH-2, a novel member of the interleukin-1 beta-converting enzyme family of cysteine proteases." J Biol Chem 270(25): 15250-15256.

Kato, T., T. Takai, T. Fujimura, H. Matsuoka, T. Ogawa, K. Murayama, A. Ishii, S. Ikeda, K. Okumura and H. Ogawa (2009). "Mite serine protease activates protease-activated receptor-2 and induces cytokine release in human keratinocytes." Allergy 64(9): 1366-1374.

Kawai, T. and S. Akira (2010). "The role of pattern-recognition receptors in innate immunity: update on Toll-like receptors." Nat Immunol 11(5): 373-384.

Kay, A. B. (2001). "Allergy and allergic diseases. First of two parts." N Engl J Med 344(1): 30-37.

Kayagaki, N., S. Warming, M. Lamkanfi, L. Vande Walle, S. Louie, J. Dong, K. Newton, Y. Qu, J. Liu, S. Heldens, J. Zhang, W. P. Lee, M. Roose-Girma and V. M. Dixit (2011). "Non-canonical inflammasome activation targets caspase-11." Nature 479(7371): 117-121.

Kayagaki, N., M. T. Wong, I. B. Stowe, S. R. Ramani, L. C. Gonzalez, S. Akashi-Takamura, K. Miyake, J. Zhang, W. P. Lee, A. Muszynski, L. S. Forsberg, R. W. Carlson and V. M. Dixit (2013). "Noncanonical inflammasome activation by intracellular LPS independent of TLR4." Science 341(6151): 1246-1249.

Khweek, A. A., K. Caution, A. Akhter, B. A. Abdulrahman, M. Tazi, H. Hassan, N. Majumdar, A. Doran, E. Guirado, L. S. Schlesinger, H. Shuman and A. O. Amer (2013). "A bacterial protein promotes the recognition of the Legionella pneumophila vacuole by autophagy." Eur J Immunol 43(5): 1333-1344.

Kim, D. Y., B. S. Park, G. U. Hong, B. J. Lee, J. W. Park, S. Y. Kim and J. Y. Ro (2011). "Anti-inflammatory effects of the R2 peptide, an inhibitor of transglutaminase 2, in a mouse model of allergic asthma, induced by ovalbumin." Br J Pharmacol 162(1): 210-225.

Kubo, M. (2017). "Innate and adaptive type 2 immunity in lung allergic inflammation." Immunol Rev 278(1): 162-172.

Lamkanfi, M., W. Declercq, M. Kalai, X. Saelens and P. Vandenabeele (2002). "Alice in caspase land. A phylogenetic analysis of caspases from worm to man." Cell Death Differ 9(4): 358-361.

Lamkanfi, M. and V. M. Dixit (2014). "Mechanisms and functions of inflammasomes." Cell 157(5): 10131022. 
Lefrancais, E., S. Roga, V. Gautier, A. Gonzalez-de-Peredo, B. Monsarrat, J. P. Girard and C. Cayrol (2012). "IL-33 is processed into mature bioactive forms by neutrophil elastase and cathepsin G." Proc Natl Acad SciU S A 109(5): 1673-1678.

Li, J., W. M. Brieher, M. L. Scimone, S. J. Kang, H. Zhu, H. Yin, U. H. von Andrian, T. Mitchison and J. Yuan (2007). "Caspase-11 regulates cell migration by promoting Aip1-Cofilin-mediated actin depolymerization." Nat Cell Biol 9(3): 276-286.

Lin, X. Y., M. S. Choi and A. G. Porter (2000). "Expression analysis of the human caspase-1 subfamily reveals specific regulation of the CASP5 gene by lipopolysaccharide and interferon-gamma." $\underline{\mathrm{J} B i o l}$ Chem 275(51): 39920-39926.

Luthi, A. U., S. P. Cullen, E. A. McNeela, P. J. Duriez, I. S. Afonina, C. Sheridan, G. Brumatti, R. C. Taylor, K. Kersse, P. Vandenabeele, E. C. Lavelle and S. J. Martin (2009). "Suppression of interleukin-33 bioactivity through proteolysis by apoptotic caspases." Immunity. 31(1): 84-98.

Madouri, F., N. Guillou, L. Fauconnier, T. Marchiol, N. Rouxel, P. Chenuet, A. Ledru, L. Apetoh, F. Ghiringhelli, M. Chamaillard, S. G. Zheng, F. Trovero, V. F. Quesniaux, B. Ryffel and D. Togbe (2015). "Caspase-1 activation by NLRP3 inflammasome dampens IL-33-dependent house dust mite-induced allergic lung inflammation." J Mol Cell Biol 7(4): 351-365.

Martinon, F. and J. Tschopp (2004). "Inflammatory caspases: linking an intracellular innate immune system to autoinflammatory diseases." Cell 117(5): 561-574.

Maunsell, K., D. G. Wraith and A. M. Cunnington (1968). "Mites and house-dust allergy in bronchial asthma." Lancet 1(7555): 1267-1270.

McAdam, A. J., A. N. Schweitzer and A. H. Sharpe (1998). "The role of B7 co-stimulation in activation and differentiation of CD4+ and CD8+ T cells." Immunol Rev 165: 231-247.

Melgert, B. N., T. B. Oriss, Z. Qi, B. Dixon-McCarthy, M. Geerlings, M. N. Hylkema and A. Ray (2010). "Macrophages: regulators of sex differences in asthma?" Am J Respir Cell Mol Biol 42(5): 595-603.

Moreira, A. P., K. A. Cavassani, R. Hullinger, R. S. Rosada, D. J. Fong, L. Murray, D. P. Hesson and C. M. Hogaboam (2010). "Serum amyloid $P$ attenuates M2 macrophage activation and protects against fungal spore-induced allergic airway disease." J Allergy Clin Immunol 126(4): 712-721.e717.

Moreira, A. P. and C. M. Hogaboam (2011). "Macrophages in allergic asthma: fine-tuning their pro- and anti-inflammatory actions for disease resolution." J Interferon Cytokine Res 31(6): 485-491.

Morita, H., S. Nakae, H. Saito and K. Matsumoto (2017). "IL-33 in clinical practice: Size matters?" J Allergy. Clin Immunol 140(2): 381-383. 
Mould, A. W., K. I. Matthaei, I. G. Young and P. S. Foster (1997). "Relationship between interleukin-5 and eotaxin in regulating blood and tissue eosinophilia in mice." J Clin Invest 99(5): 1064-1071.

Munday, N. A., J. P. Vaillancourt, A. Ali, F. J. Casano, D. K. Miller, S. M. Molineaux, T. T. Yamin, V. L. Yu and D. W. Nicholson (1995). "Molecular cloning and pro-apoptotic activity of ICErellI and ICErellI, members of the ICE/CED-3 family of cysteine proteases." J Biol Chem 270(26): 15870-15876.

Na, H., M. Cho and Y. Chung (2016). "Regulation of Th2 Cell Immunity by Dendritic Cells." Immune Netw 16(1): 1-12.

Pelletier, M., L. Maggi, A. Micheletti, E. Lazzeri, N. Tamassia, C. Costantini, L. Cosmi, C. Lunardi, F. Annunziato, S. Romagnani and M. A. Cassatella (2010). "Evidence for a cross-talk between human neutrophils and Th17 cells." Blood 115(2): 335-343.

Platts-Mills, T. A. and M. D. Chapman (1987). "Dust mites: immunology, allergic disease, and environmental control." J Allergy_ Clin Immunol 80(6): 755-775.

Rathinam, V. A., S. K. Vanaja, L. Waggoner, A. Sokolovska, C. Becker, L. M. Stuart, J. M. Leong and K. A. Fitzgerald (2012). "TRIF licenses caspase-11-dependent NLRP3 inflammasome activation by gramnegative bacteria." Cell 150(3): 606-619.

Ricci, M., O. Rossi, M. Bertoni and A. Matucci (1993). "The importance of Th2-like cells in the pathogenesis of airway allergic inflammation." Clin Exp Allergy. 23(5): 360-369.

Ritter, A. T., K. L. Angus and G. M. Griffiths (2013). "The role of the cytoskeleton at the immunological synapse." Immunol Rev 256(1): 107-117.

Roche, N., T. C. Chinet and G. J. Huchon (1997). "Allergic and nonallergic interactions between house dust mite allergens and airway mucosa." Eur Respir J 10(3): 719-726.

Romagnani, S. (2000). "The role of lymphocytes in allergic disease." J Allergy Clin Immunol 105(3): 399408.

Romagnani, S. (2004). "Immunologic influences on allergy and the TH1/TH2 balance." J Allergy Clin Immunol 113(3): 395-400.

Sanchez-Borges, M., E. Fernandez-Caldas, W. R. Thomas, M. D. Chapman, B. W. Lee, L. Caraballo, N. Acevedo, F. T. Chew, I. J. Ansotegui, L. Behrooz, W. Phipatanakul, R. Gerth van Wijk, D. Pascal, N. Rosario, M. Ebisawa, M. Geller, S. Quirce, S. Vrtala, R. Valenta, M. Ollert, G. W. Canonica, M. A. Calderon, C. S. Barnes, A. Custovic, S. Benjaponpitak and A. Capriles-Hulett (2017). "International consensus (ICON) on: clinical consequences of mite hypersensitivity, a global problem." World Allergy_Organ J 10(1): 14.

Schauvliege, R., J. Vanrobaeys, P. Schotte and R. Beyaert (2002). "Caspase-11 gene expression in response to lipopolysaccharide and interferon-gamma requires nuclear factor-kappa B and signal 
transducer and activator of transcription (STAT) 1." J Biol Chem 277(44): 41624-41630.

Schmitz, J., A. Owyang, E. Oldham, Y. Song, E. Murphy, T. K. McClanahan, G. Zurawski, M. Moshrefi, J. Qin, X. Li, D. M. Gorman, J. F. Bazan and R. A. Kastelein (2005). "IL-33, an interleukin-1-like cytokine that signals via the IL-1 receptor-related protein ST2 and induces T helper type 2-associated cytokines." Immunity 23(5): 479-490.

Sica, A. and A. Mantovani (2012). "Macrophage plasticity and polarization: in vivo veritas." J Clin Invest 122(3): 787-795.

Sun, Y. C., Q. T. Zhou and W. Z. Yao (2005). "Sputum interleukin-17 is increased and associated with airway neutrophilia in patients with severe asthma." Chin Med J (Engl). 118(11): 953-956.

Sundaram, K., S. Mitra, M. A. Gavrilin and M. D. Wewers (2015). "House Dust Mite Allergens and the Induction of Monocyte Interleukin 1 beta Production That Triggers an IkappaBzeta-Dependent Granulocyte Macrophage Colony-Stimulating Factor Release from Human Lung Epithelial Cells." Am J Respir Cell Mol Biol 53(3): 400-411.

Talabot-Ayer, D., C. Lamacchia, C. Gabay and G. Palmer (2009). "Interleukin-33 is biologically active independently of caspase-1 cleavage." J Biol Chem 284(29): 19420-19426.

Thomas, W. R. (2012). "House dust allergy and immunotherapy." Hum Vaccin Immunother 8(10): 14691478.

Thomas, W. R., B. J. Hales and W. A. Smith (2010). "House dust mite allergens in asthma and allergy." Trends Mol Med 16(7): 321-328.

Wahn, U., S. Lau, R. Bergmann, M. Kulig, J. Forster, K. Bergmann, C. P. Bauer and I. GuggenmoosHolzmann (1997). "Indoor allergen exposure is a risk factor for sensitization during the first three years of life." J Allergy_Clin Immunol 99(6 Pt 1): 763-769.

Wambre, E., E. A. James and W. W. Kwok (2012). "Characterization of CD4+ T cell subsets in allergy." Curr Opin Immunol 24(6): 700-706.

Wang, S., M. Miura, Y. K. Jung, H. Zhu, E. Li and J. Yuan (1998). "Murine caspase-11, an ICE-interacting protease, is essential for the activation of ICE." Cell 92(4): 501-509.

Willart, M. A., K. Deswarte, P. Pouliot, H. Braun, R. Beyaert, B. N. Lambrecht and H. Hammad (2012). "Interleukin-1alpha controls allergic sensitization to inhaled house dust mite via the epithelial release of GM-CSF and IL-33." J Exp Med 209(8): 1505-1517.

Willart, M. A. and B. N. Lambrecht (2009). "The danger within: endogenous danger signals, atopy and asthma." Clin Exp Allergy. 39(1): 12-19. 
Williams, R. C. and R. J. Gibbons (1972). "Inhibition of bacterial adherence by secretory immunoglobulin A: a mechanism of antigen disposal." Science 177(4050): 697-699.

Woodfolk, J. A. (2007). "T-cell responses to allergens." J Allergy Clin Immunol 119(2): 280-294; quiz 295286.

Yang, J., Y. Zhao and F. Shao (2015). "Non-canonical activation of inflammatory caspases by cytosolic LPS in innate immunity." Curr Opin Immunol 32: 78-83.

Yu, S., H. Y. Kim, Y. J. Chang, R. H. DeKruyff and D. T. Umetsu (2014). "Innate lymphoid cells and asthma." J Allergy_Clin Immunol 133(4): 943-950; quiz 951.

Zaslona, Z., E. Flis, M. M. Wilk, R. G. Carroll, E. M. Palsson-McDermott, M. M. Hughes, C. Diskin, K. Banahan, D. G. Ryan, A. Hooftman, A. Misiak, J. Kearney, G. Lochnit, W. Bertrams, T. Greulich, B. Schmeck, O. J. McElvaney, K. H. G. Mills, E. C. Lavelle, M. Wygrecka, E. M. Creagh and L. A. J. O'Neill (2020). "Caspase-11 promotes allergic airway inflammation." Nat Commun 11(1): 1055.

Zhong, B., X. Yang, Q. Sun, L. Liu, X. Lan, J. Tian, Q. He, W. Hou, H. Liu, C. Jiang, N. Gao and S. Lu (2014). "Pdcd 4 modulates markers of macrophage alternative activation and airway remodeling in antigen-

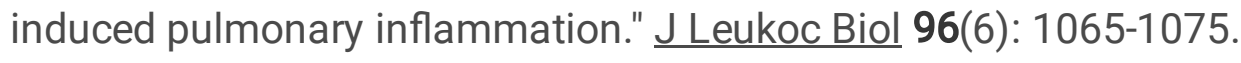

Zimmermann, N., G. K. Hershey, P. S. Foster and M. E. Rothenberg (2003). "Chemokines in asthma: cooperative interaction between chemokines and IL-13." J Allergy_Clin Immunol 111(2): 227-242; quiz 243.

\section{Figures}


Fig.1 HDM 4h HDM 24h

NT $\begin{array}{lllllllll}25 & 50 & 100 & 200 & \text { NT } & 25 \quad 50 & 100 & 200\end{array}$

Caspase-1

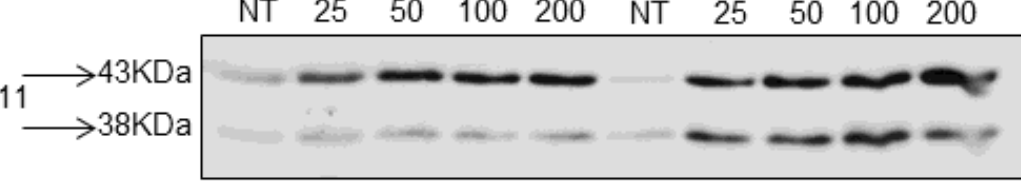

$\mathrm{GAPDH} \longrightarrow 37 \mathrm{KDa}$

IL-4

B

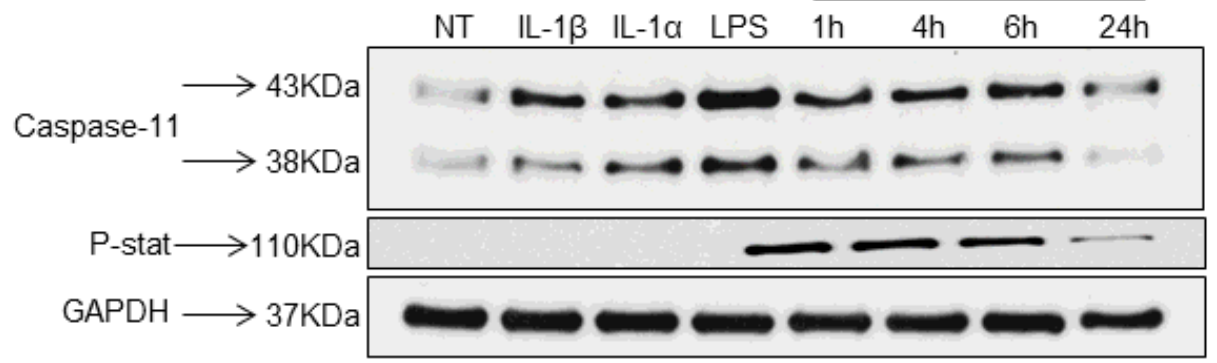

IL-13

C

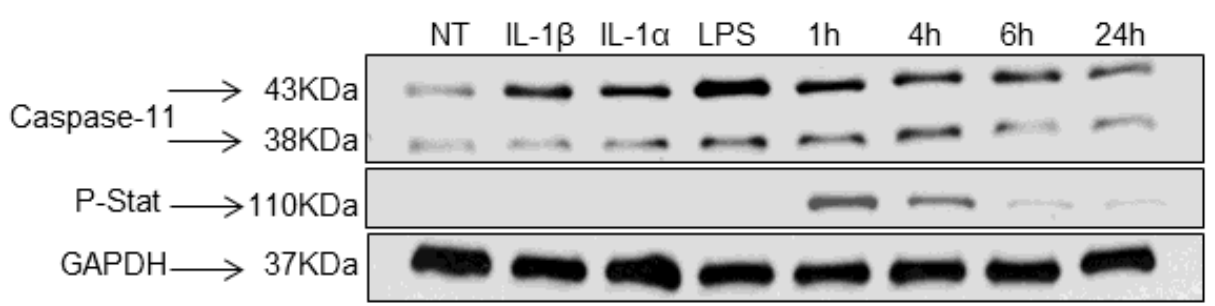

D

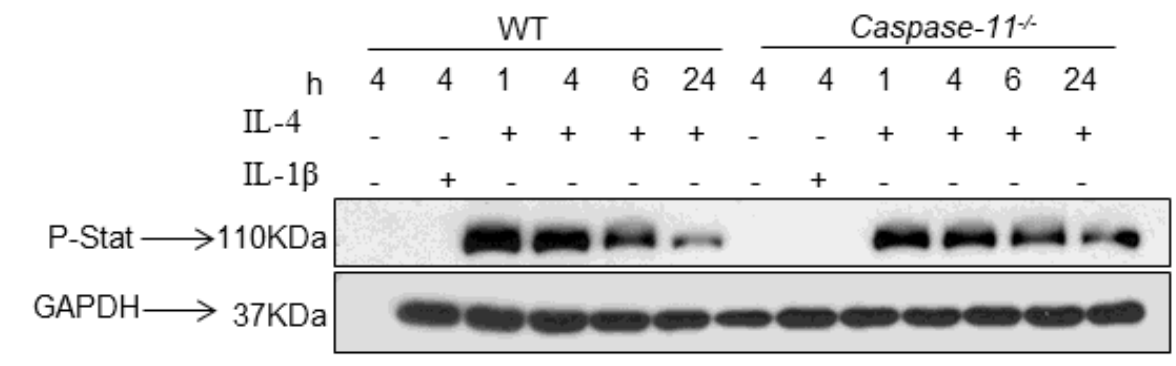

E

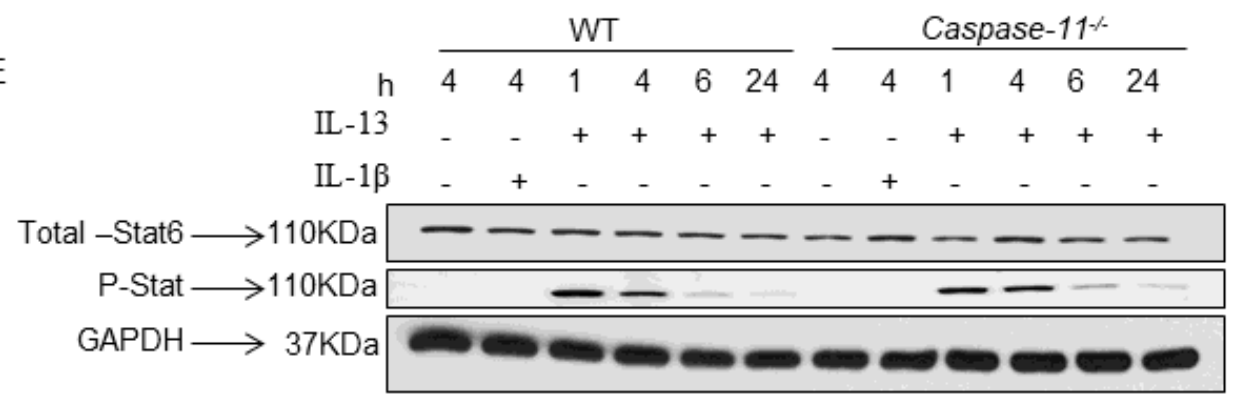

\section{Figure 1}

HDMs, IL-4 and IL-13 cytokines promote caspase-11 expression in macrophages derived from WT mice. WT macrophages were not treated (NT) or treated with different concentrations of HDM $(25,50,100$ and $200 \mu \mathrm{g} / \mathrm{ml}$ ) for 4 or $24 \mathrm{~h}$. Caspase-11 expression was examined by Western blotting. GAPDH was used as a loading control (A). WT macrophages were treated with several inflammatory stimuli (IL-1 1 , IL-1a or LPS) or stimulated with different concentrations of IL-4 (5ng/mL) (B) or IL-13 (20ng/mL) (C) for 1, 4, 6 
and $24 \mathrm{~h}$ and compared to NT samples. Western blot membranes were immunoblotted with capsase-11 or phospho-STAT6 antibodies and GAPDH was used as a loading control. WT or caspase-11-/macrophages were NT, treated with IL-1 $\beta$ or stimulated with different concentrations of IL-4 $(5 \mathrm{ng} / \mathrm{mL})(\mathrm{D})$ or IL-13 (20ng/mL) (E) for 1, 4, 6 and $24 \mathrm{~h}$. Membranes were immunoblotted with total Stat6, phosphoSTAT6 antibodies, GAPDH was used as a loading control. Two independent experiments were performed and lead to the same results. Representative blots are shown from one of the two experiments $(n=2)$.

Fig.2
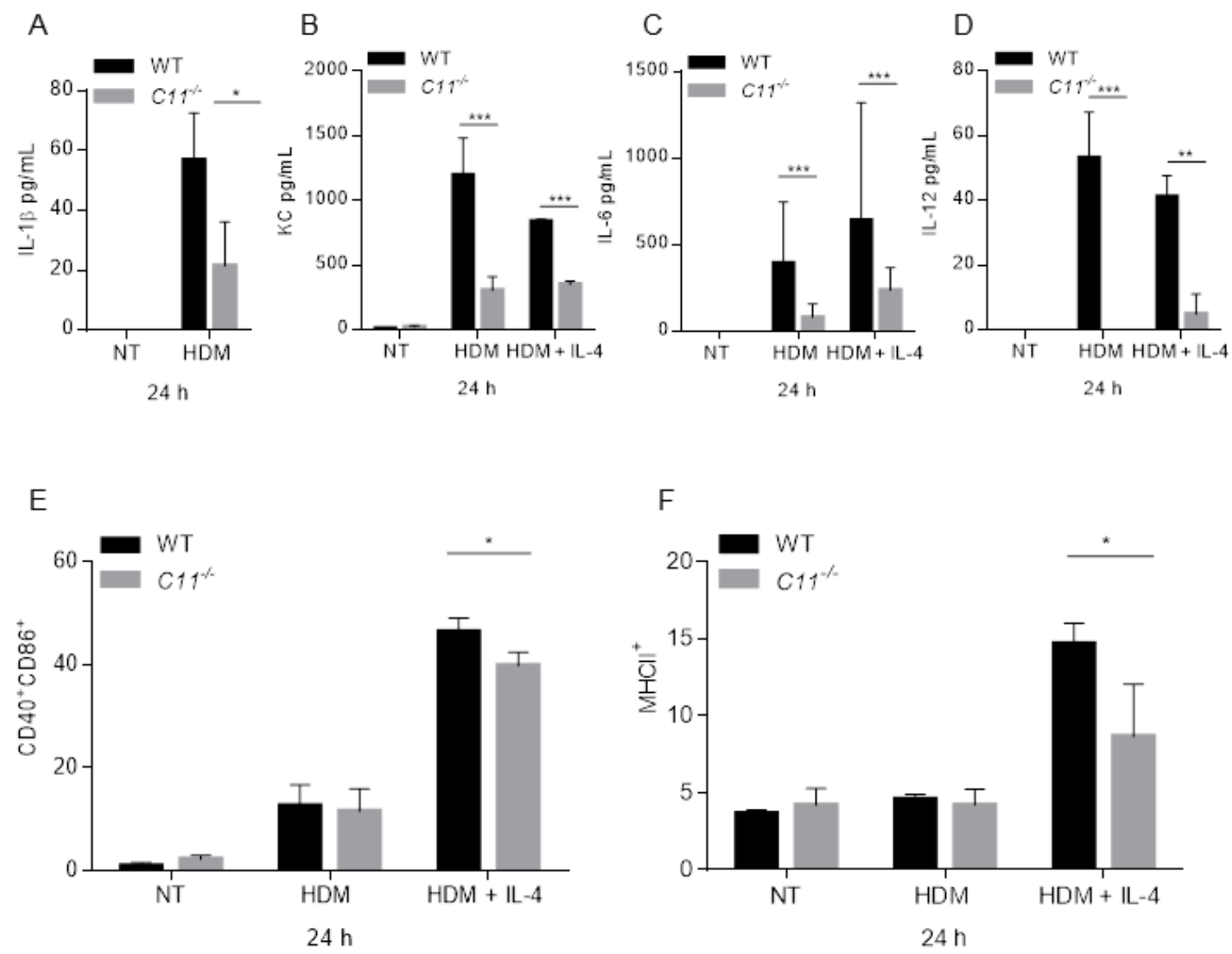

G

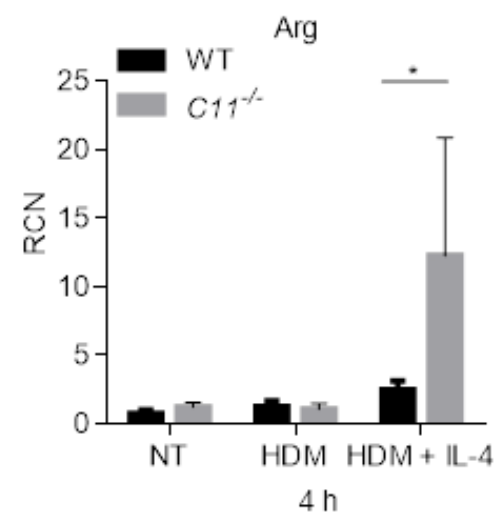

$\mathrm{H}$

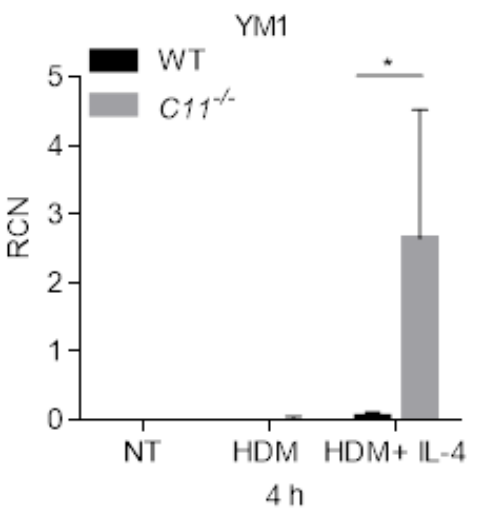

I

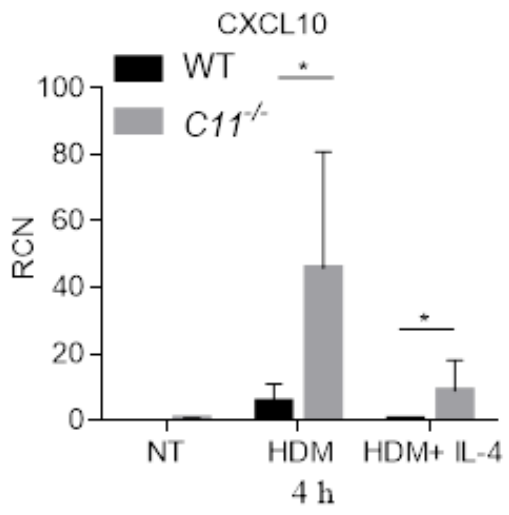

Figure 2 
Caspase-11-/- macrophages show reduced release of proinflammatory cytokines and reduced expression of costimulatory molecules post-HDM treatment. Level of IL-1 $\beta$ released in the supernatants of WT or caspase-11-/- macrophages treated with $100 \mu \mathrm{g} / \mathrm{mL}$ of HDM $24 \mathrm{~h}$ post-treatment (A). Data represent the mean $\pm S D(n=4)$ obtained from four independent experiments. Multiple t-tests performed for statistical analysis, ${ }^{*} p<0.05$. Concentrations of keratinocyte-derived protein chemokine (KC) (B), IL-6 (C), and IL-12 (D) released in supernatants from WT and caspase-11-/- macrophages either un-treated (NT), treated with HDM $(100 \mu \mathrm{g} / \mathrm{mL})$, pre-stimulated with IL-4 $(5 \mathrm{ng} / \mathrm{mL})$ then treated with HDM and IL-4 for $24 \mathrm{~h}$. Data represent the mean $\pm S D(n=4)$ obtained from four independent experiments. Multiple t-tests performed for statistical analysis, $* \star p<0.01, * \star \star p<0.001$. Expression of costimulatory molecules CD40 and CD86 $(E)$, and $\mathrm{MHClI}(\mathrm{F})$ by flow cytometry $24 \mathrm{~h}$ post- HDM treatment. Data represent the mean $\pm \mathrm{SD}(\mathrm{n}=3)$ obtained from three independent experiments. Multiple t-tests performed for statistical analysis, * $\mathrm{p}<$ 0.05. WT and caspase-11-/- macrophages either NT, treated with HDM $(100 \mu \mathrm{g} / \mathrm{mL})$, pre-stimulated with $\mathrm{IL}-4(5 \mathrm{ng} / \mathrm{mL})$ then treated with HDM and IL-4 for $4 \mathrm{~h}$. Expression of M2 (Arg1, YM1) or M1 (CXCL10) markers by RT-qPCR $4 \mathrm{~h}$ post-treatment $(\mathrm{G}, \mathrm{H} \& \mathrm{I})$. RCN on the $\mathrm{Y}$ axis represents relative copy number. Data represent the mean $\pm S D(n=3)$ obtained from three independent experiments. Multiple t-tests performed for statistical analysis, ${ }^{*} p<0.05$. 
Fig.3

A

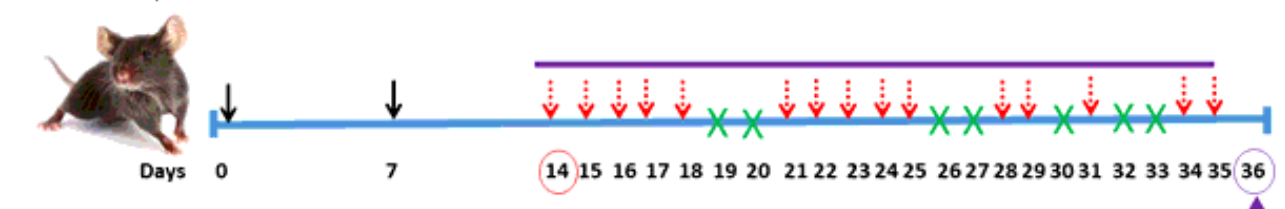

B

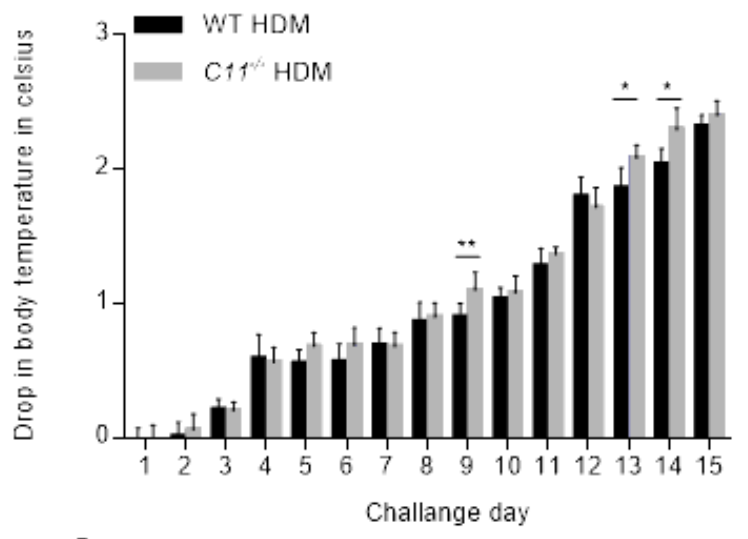

$\mathrm{C}$

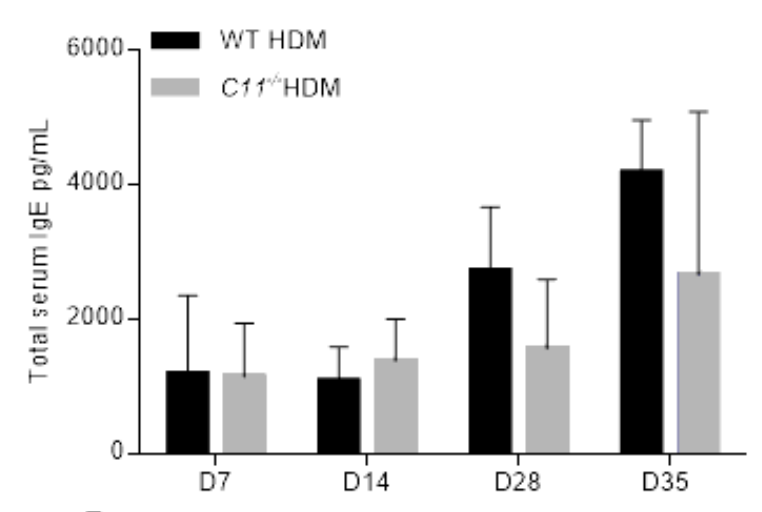

D

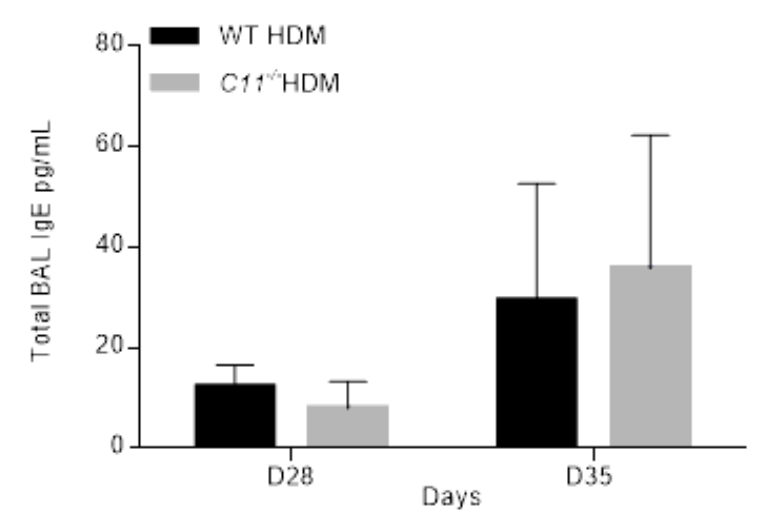

E

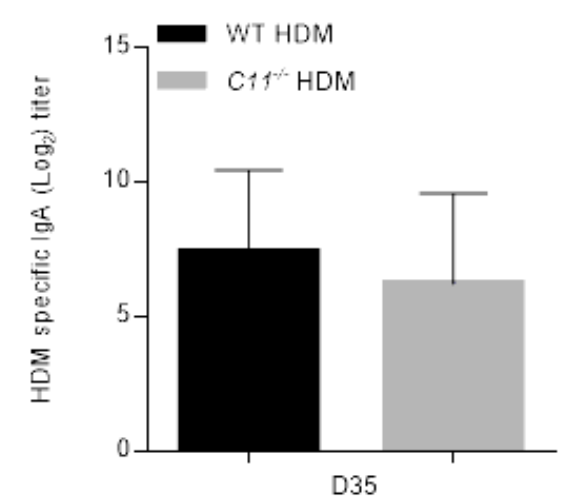

$\mathrm{F}$
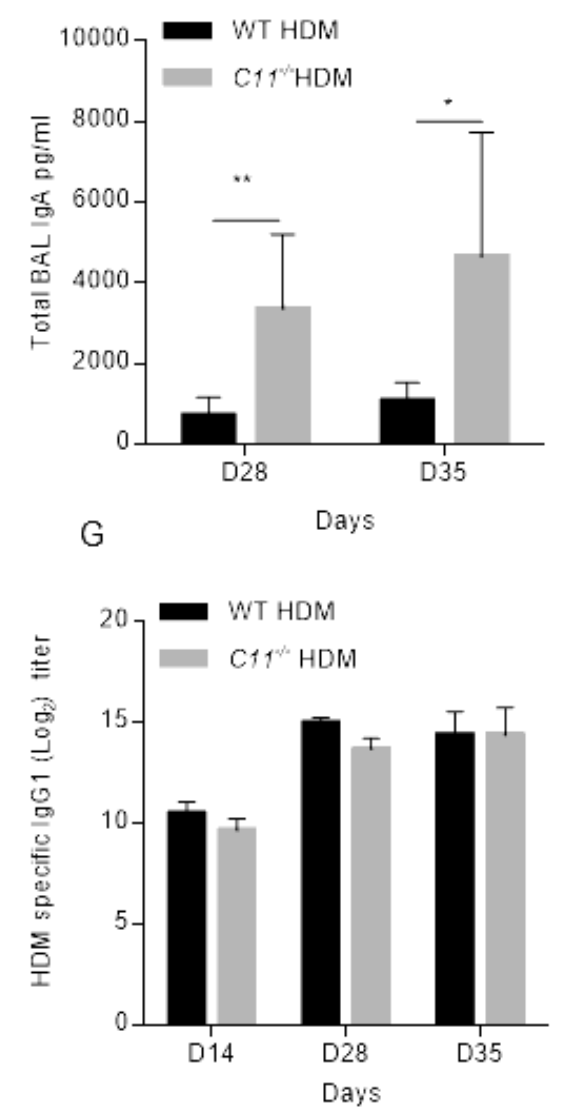

\section{Figure 3}

HDM sensitization and challenge promotes differential allergic inflammation and antibody response in live WT and caspase-11-/- mice. Schematic of HDM model (A), five WT and five caspase-11-/- mice were sensitized with alum $+100 \mu \mathrm{g} \mathrm{HDM}$ on day 0 and 7 intra-peritoneally (solid arrows). Mice were challenged with 15 doses of HDM intranasally $(25 \mu \mathrm{g})$ as indicated (dashed arrows). Days without a challenge are indicated by $(X)(A)$. The experiment was done twice with seven mice per group in the first in vivo 
experiment and 5 mice per group in the second in vivo experiment and lead to similar results. Drop in surface body temperature after intra-nasal challenges with HDM was measured before and thirty minutes after each challenge (B). Data indicates the difference in body temperature before and after each challenge. The experiment was done twice with seven mice per group in the first in vivo experiment and 5 mice per group in the second in vivo experiment and lead to similar results. Data represent the mean \pm SD $(n=5)$ obtained from the second in vivo experiment. Two-way ANOVA performed for statistical analysis, * $p<0.05,{ }^{\star *} p<0.01$, the experiment was performed twice. Total IgE level was quantified in serum (C) and BAL fluid samples (D) collected before sensitization (day 0), after sensitization with HDM and alum (day 14), day 28 , and $24 \mathrm{~h}$ after the last challenge (day 35). HDM-specific IgA was quantified on day 28 and 35 (E), and total IgA level was quantified in BAL fluid on day 35 (F). HDM-specific IgG1 was quantified in serum samples collected before sensitization (day 0), after sensitization with HDM and alum (day 14), day 28 , and $24 \mathrm{~h}$ after the last challenge (day 35$)(\mathrm{G})$. Day 0,14 and $(28,35)$ represent naïve, sensitized, and sensitized + challenged mice. The experiment was done twice with seven mice per group in the first in vivo experiment and 5 mice per group in the second in vivo experiment and lead to similar results. Data represent the mean $\pm S D(n=5)$ obtained from the second in vivo experiment. The experiment was done twice and lead to similar results. Multiple t-tests performed for statistical analysis, ${ }^{*} p<0.05,{ }^{*} p<0.01$, the experiment was performed twice. 
Fig.4
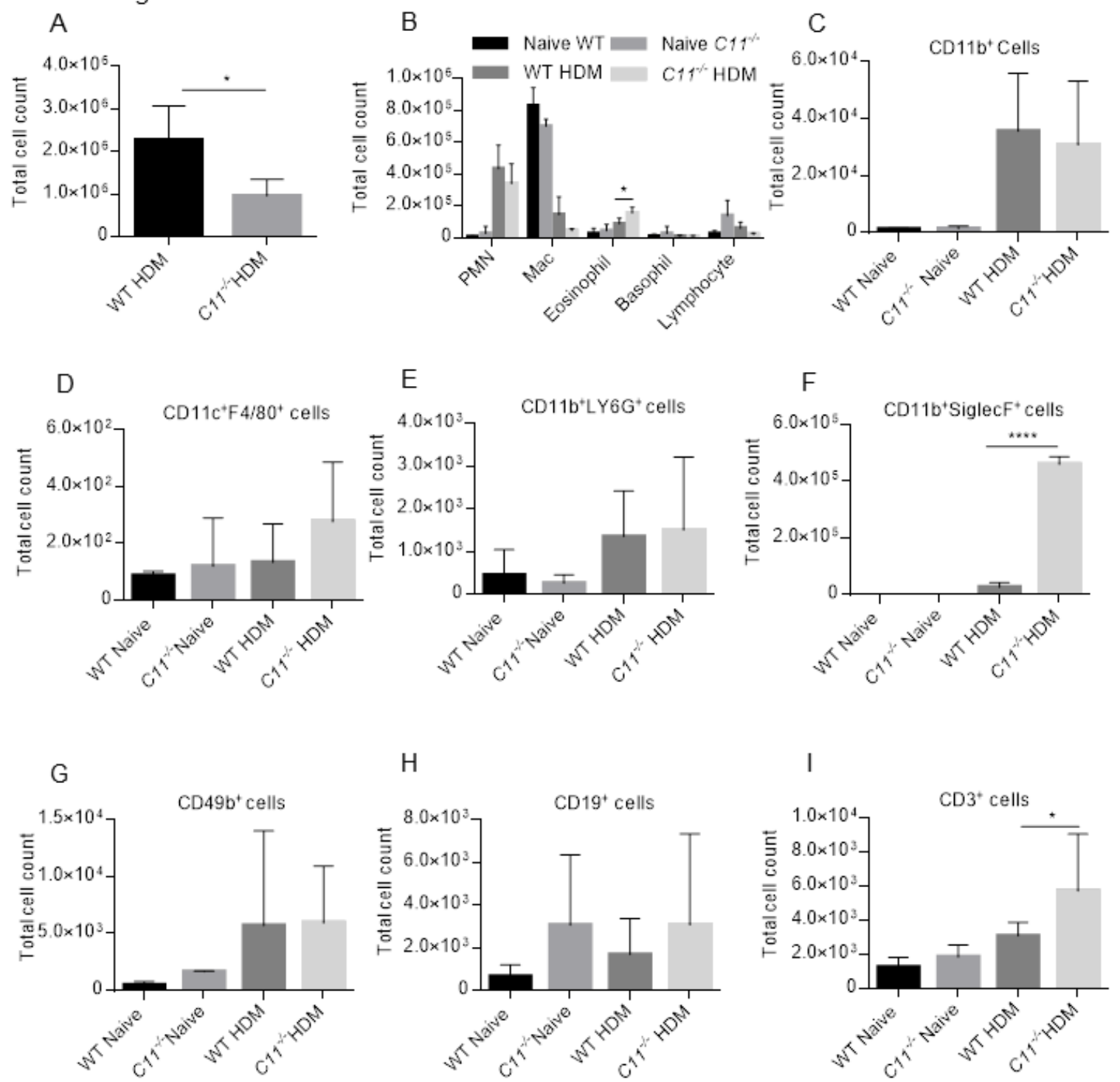

$\mathrm{H}$

$$
\text { J }
$$
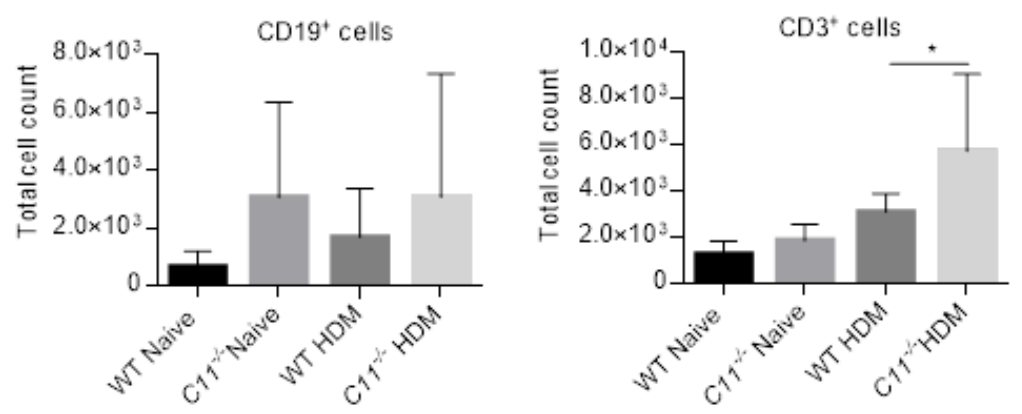

K
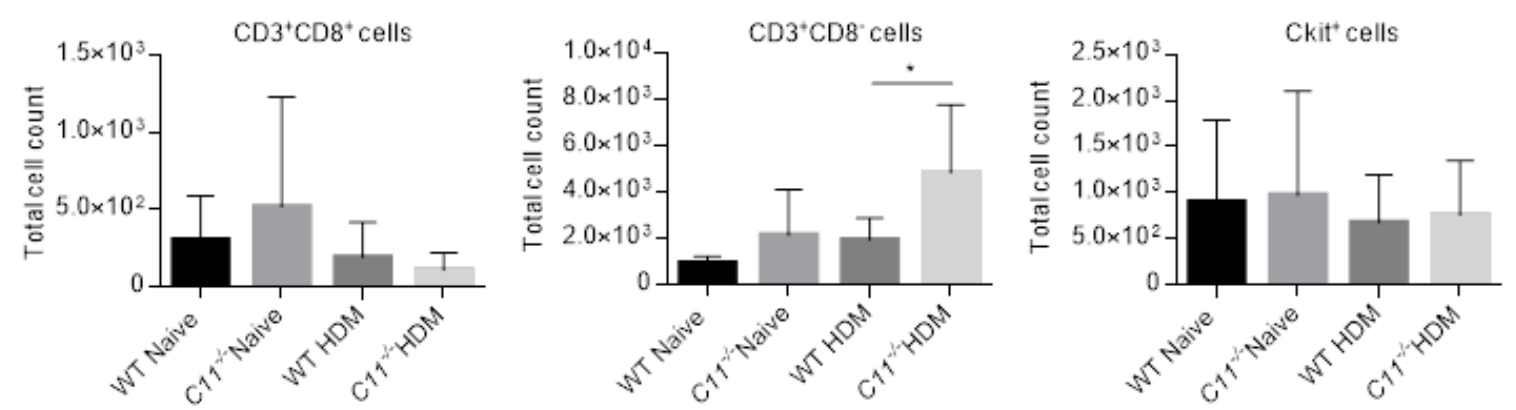

\section{Figure 4}

WT and caspase-11-/- mice show differential cellular infiltration in their BAL fluid in response to HDM. Immune cells in bronchial alveolar lavage (BAL) fluids of WT or caspase-11-/- mice sensitized and challenged with HDM. Twenty-four hours following the last HDM challenge, cells were isolated by centrifugation and counted with a hemocytometer (A). Total BAL fluid cells were spotted on the cytospin chamber, stained and counted (B). The experiment was done twice with seven mice per group in the first 
in vivo experiment and 5 mice per group in the second in vivo experiment and lead to similar results. Data represent the mean $\pm S D(n=4)$ per group obtained from the second in vivo experiment. Multiple t-tests performed for statistical analysis, ${ }^{*} p<0.05$. Specific cell populations in the BAL fluids were determined by staining cells with several markers followed by flow cytometry. Flow markers are (CD11b+), $(\mathrm{CD} 11 \mathrm{C}+\mathrm{F} 480+),(\mathrm{CD} 11 \mathrm{~b}+\mathrm{Ly} 6 \mathrm{G}+),(\mathrm{CD} 11 \mathrm{~b}+\mathrm{SigleCF}+),(\mathrm{CD} 49 \mathrm{~b}+),(\mathrm{CD} 19+), \mathrm{CD} 3+,(\mathrm{CD} 3+\mathrm{CD} 8+),(\mathrm{CD} 3+\mathrm{CD} 8-)$ and $(\mathrm{C}-\mathrm{kit}+)(\mathrm{C}-\mathrm{L})$. The experiment was done twice with seven mice per group in the first in vivo experiment and 5 mice per group in the second in vivo experiment. Data represent the mean $\pm S D(n=9)$ per group pooled from the two experiments. Multiple t-tests performed for statistical analysis, ${ }^{*} p<0.05$, $\star \star p<0.01, * \star * p<0.001$ 
Fig.5
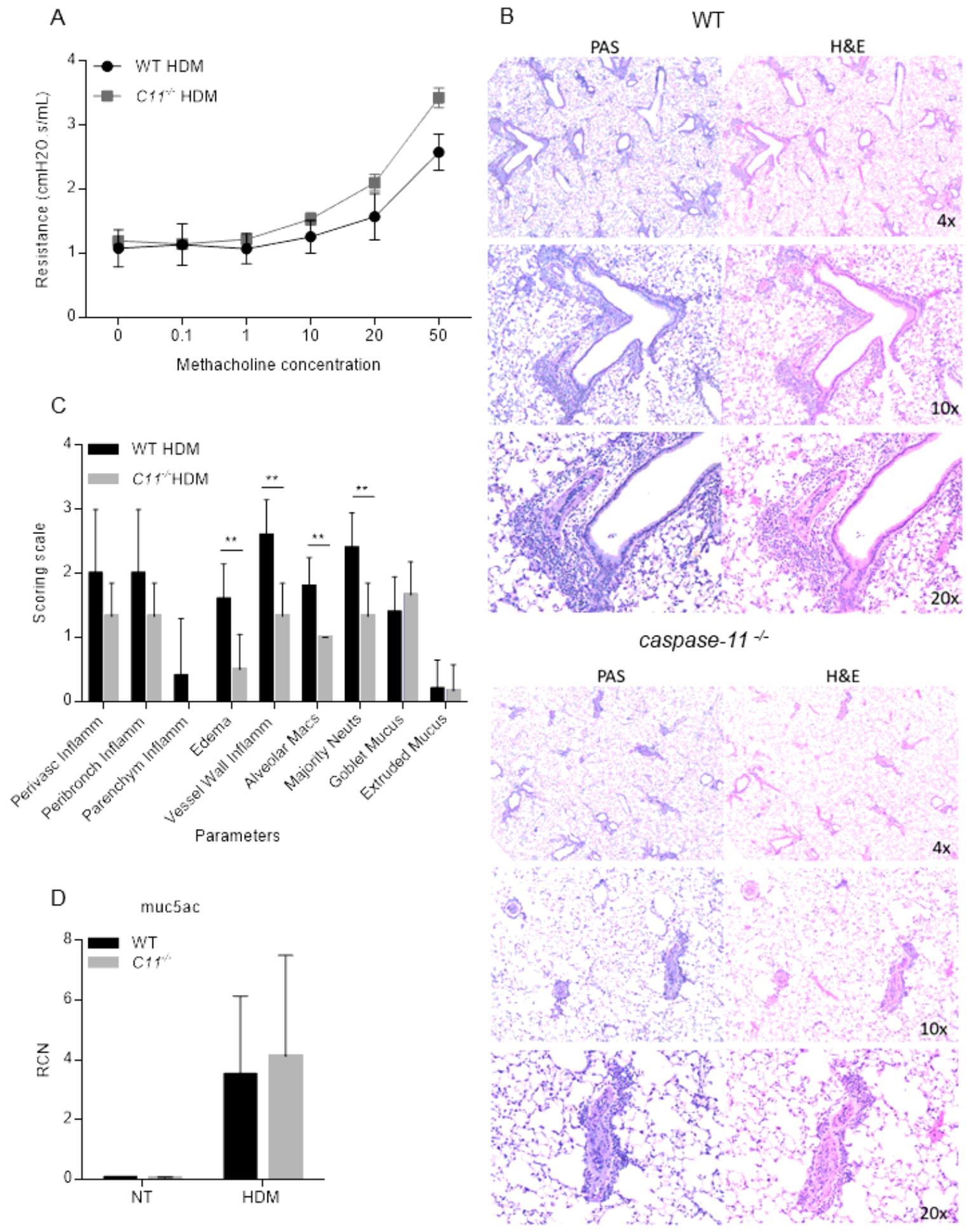

\section{Figure 5}

Caspase-11-/- mice show reduced lung inflammation with similar airway resistance and mucus production. Airway hyper-responsiveness to increasing concentrations of methacholine was measured 24 $\mathrm{h}$ after the last HDM challenge. Airway hyper-responsiveness was measured by recording changes in lung resistance of WT and caspase-11-/- mice (A). The experiment was performed once with five mice per genotype. Data represent the mean \pm SD $(n=5)$ per group obtained from one experiment. Two-way ANOVA 
performed for statistical analysis. A linear mixed model was used to take account of the correlation among observations from the same mouse within the same cage. No significant difference was seen between caspase-11-/- and WT on the lung contraction averaged across the drug concentrations. Representative sections showing reduced lung inflammation in caspase-11-/- mice exposed to HDM compared to WT (B). The experiment was done twice with seven mice per group in the first in vivo experiment and 5 mice per group in the second in vivo experiment. Representative images are shown from the second in vivo experiment. Lung sections were formalin-fixed, stained with periodic acid Schiff reagent (PAS) or H\& E. Magnifications are 4x, 10x and 40x. Quantification of inflammation and cellular infiltration in the lungs scored from images were done in a blinded fashion by a pathologist of the Comparative Pathology and Mouse Phenotyping Shared Resource at the Ohio State University (C). Data represent the mean $\pm S D(n=5)$ per group obtained from the second in vivo experiment. Multiple t tests performed for statistical analysis, * $P<0.05$. Representative $(n=2)$ expression of muc5ac mRNA was measured by quantitative PCR obtained from the second in vivo experiment (D). 
Fig.6

A

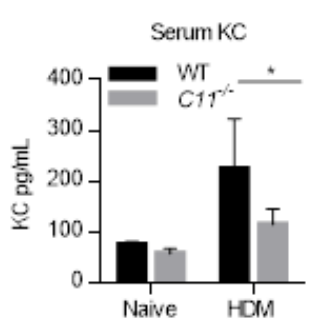

E

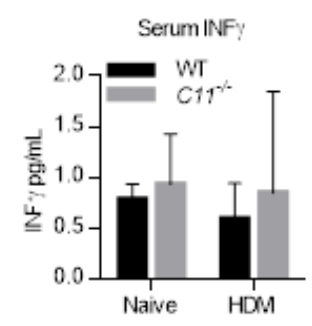

I

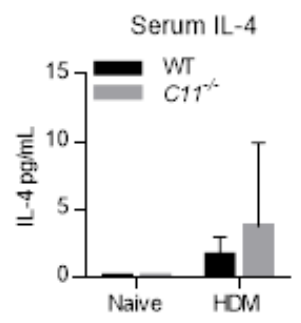

M

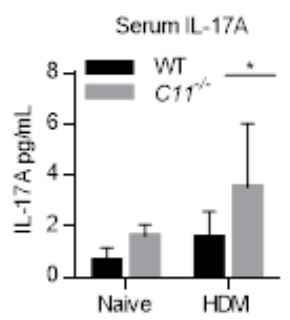

B

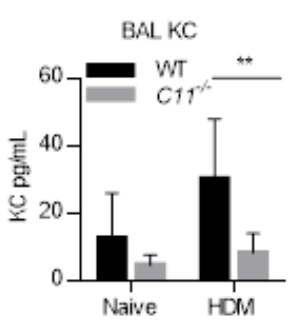

F

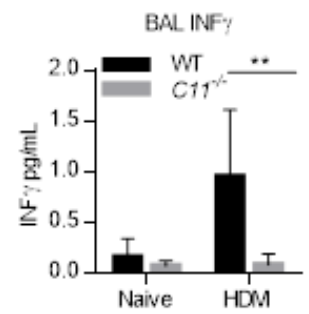

J

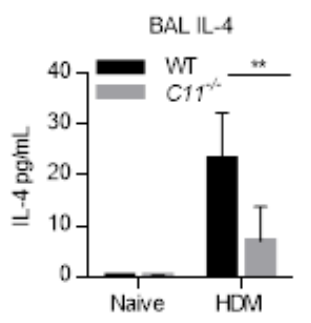

N

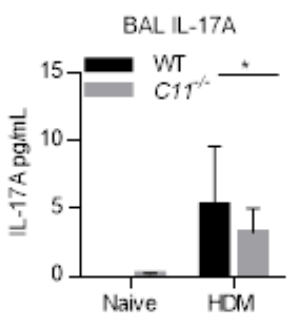

C

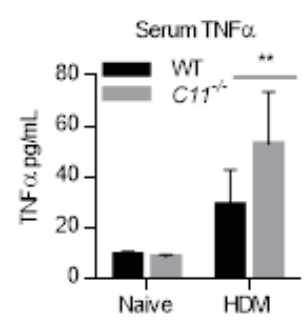

G

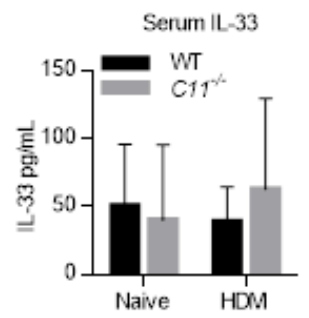

K

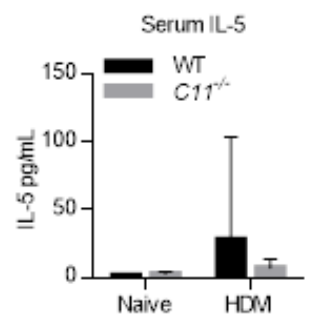

O

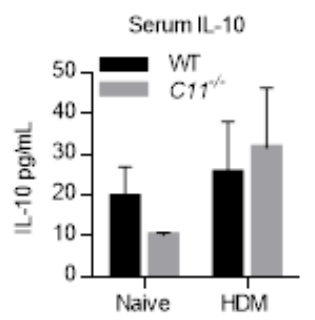

D

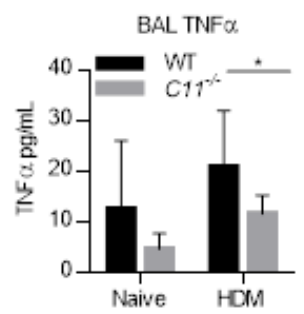

$\mathrm{H}$

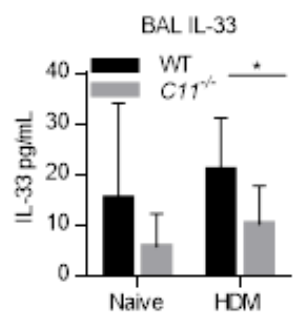

L

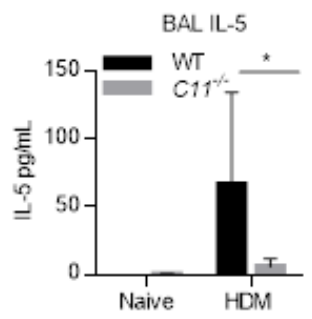

P

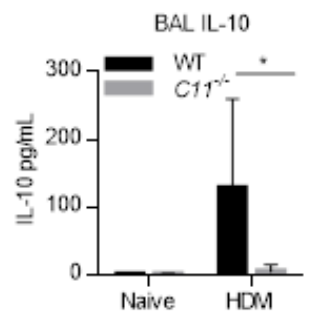

\section{Figure 6}

Serum and BAL from caspase-11-/- mice show differential levels of Th1 and Th2 cytokines compared to WT. Sera and BAL fluid samples were obtained from mice on day 35 post-HDM challenge. Level of serum and BAL fluid cytokines were quantified my multiplex MSD electrochemiluminesence (OSU core facility). Day 0 represents serum obtained from naïve animals, while day 35 represents serum obtained from animals exposed to HDM for 35 days. Serum and BAL KC (A \& B), TNFa (C \& D), INFy (E \& F), IL-33 (G \& 
H), IL-4 level (I \& J), IL-5 (K \& L), IL-17A (M \& N), IL-10 level (O \& P). Data represent the mean \pm SD $(n=4)$ per group obtained from the second in vivo experiment. Multiple t tests performed for statistical analysis, ${ }^{*} \mathrm{P}<0.05, * \star \mathrm{p}<0.01$.

\section{Supplementary Files}

This is a list of supplementary files associated with this preprint. Click to download.

- AbuKhweekscoringrubric.pdf

- Supplementaryfig.1.tif 